\title{
HOW MUCH IS EMPLOYMENT INCREASED BY CUTTING LABOR COSTS? ESTIMATING THE ELASTICITY OF JOB CREATION
}

\author{
Paul Beaudry \\ David A. Green \\ Benjamin M. Sand \\ Working Paper 15790 \\ http://www.nber.org/papers/w15790 \\ NATIONAL BUREAU OF ECONOMIC RESEARCH \\ 1050 Massachusetts Avenue \\ Cambridge, MA 02138 \\ February 2010
}

We thank Chris Bidner, David Card, Giovanni Gallipoli, Patrick Kline, Alex Lefter, Kevin Milligan and seminar participants at the University of California -- Berkeley, University of Bristol, University of Southampton and the University of British Columbia for helpful comments and suggestions. The views expressed herein are those of the authors and do not necessarily reflect the views of the National Bureau of Economic Research.

NBER working papers are circulated for discussion and comment purposes. They have not been peerreviewed or been subject to the review by the NBER Board of Directors that accompanies official NBER publications.

(C) 2010 by Paul Beaudry, David A. Green, and Benjamin M. Sand. All rights reserved. Short sections of text, not to exceed two paragraphs, may be quoted without explicit permission provided that full credit, including $(\subset$ notice, is given to the source. 
How Much Is Employment Increased by Cutting Labor Costs? Estimating the Elasticity of Job Creation

Paul Beaudry, David A. Green, and Benjamin M. Sand

NBER Working Paper No. 15790

February 2010

JEL No. E24,J21,J23,J3

\begin{abstract}
$\underline{\text { ABSTRACT }}$
In search and bargaining models, the effect of higher wages on employment is determined by the elasticity of the job creation curve. In this paper, we use U.S. data over the 1970-2007 period to explore whether labor market outcomes abide by the restrictions implied by such models and to evaluate the elasticity of the job creation curve. The main difference between a job creation curve and a standard demand curve is that the former represents a relationship between wages and employment rates, while the latter represents a relationship between wages and employment levels. Although this distinction is quite simple, it has substantive implications for the identification of the effect of higher wages on employment. The main finding of the paper is that U.S. labor market outcomes observed at the city-industry level appear to conform well to the restrictions implied by search and bargaining theory and, using 10-year differences, we estimate the elasticity of the job creation curve with respect to wages to be -0.3 . We interpret this relatively low elasticity as reflecting a low propensity for individuals to become more entrepreneurial and create more jobs when labor costs are lower and variable profits are higher.
\end{abstract}

\author{
Paul Beaudry \\ Department of Economics \\ University of Oxford and \\ University of British Columbia \\ Manor Road Building, Manor Road \\ Oxford, UK, OX1 3UQ \\ and NBER \\ paul.beaudry@economics.ox.ac.uk \\ David A. Green \\ Department of Economics \\ University of British Columbia \\ 997-1873 East Mall \\ Vancouver, B.C. \\ Canada, V6T 1Z1 \\ green@econ.ubc.ca
}

\author{
Benjamin M. Sand \\ Department of Economics \\ University of British Columbia \\ 997-1873 East Mall \\ Vancouver, B.C. \\ Canada, V6T 1Z1 \\ bmsand@interchange.ubc.ca
}




\section{Introduction}

The evaluation of policies or institutions that change labor costs requires a clear understanding of how such changes affect employment. Discussions of numerous policies, including payroll taxes, job security legislation, minimum wages and policies related to worker benefits are commonly framed in terms of whether they will "kill" jobs or, if cut, help create new ones. ${ }^{1}$ As a recent example, in debates about stagnant employment outcomes as economies emerge from recession, some analysts have argued that cutting labor costs is the key to re-starting employment growth. Embedded in such a claim is the view that higher labor costs substantially reduce aggregate employment. The evidence on this, however, is rather mixed. Many of the studies that examine the direct impacts of policy shifts - such as payroll tax changes find only modest impacts on aggregate employment (Blau and Kahn, 1999), implying rather inelastic labor demand curves. This is the same conclusion reached in much of the literature directly estimating labor demand elasticities (Hamermesh, 1993). On the other hand, studies of regional responses to supply shocks tend to find quite small wage impacts, implying very elastic labor demand curves (Blanchard and Katz, 1992; Krueger and Pischke, 1997). ${ }^{2}$ Further variation in estimates arises because different studies use different measures of employment outcomes (either employment rates or employment levels), often without a clear reference to theory to support their choice. Thus, policy makers face a confusing array of predictions about the employment impacts of policies that affect labor costs either directly or indirectly.

Attempts to provide estimates of the effects of labor costs on employment must deal with the inherent endogeneity problem stemming from the fact that wages and employment are jointly determined. In this paper, we provide estimates of the effects of labor costs on employment using a search and bargaining model to help guide and motivate our empirical strategy. We adopt this modeling perspective because it offers new insights regarding how to estimate the effects of labor costs on employment and it imposes simple testable implications which we can evaluate with available data. In addition, the model provides a potential explanation for disparities among earlier estimates of labor demand elasticities related to the use of different forms of variation and different dependent variables.

In search and bargaining models, labor demand is determined by an equilibrium relationship known as the job creation curve. This curve reflects employers' comparisons of the expected cost to the expected benefit of opening and maintaining a vacancy. With unrestricted entry, in equilibrium these costs and benefits must just equal one another at the margin. More specifically, this zero profit condition implies that a rise in wages (which reduces the benefits of a filled job for the firm), must be offset by lower vacancy creation costs. Since the cost of a vacancy is increasing in how long it takes to fill it, in equilibrium the tightness of the labor market (i.e., the employment rate) must fall when wages rise. This equilibrium relationship

\footnotetext{
${ }^{1}$ For example, the California Chamber of Commerce releases an annual list of "job killer" bills which they claim identifies legislation that will "decimate economic and job growth in California". Often the identified bills contain "workplace mandates" which are suggested to increase labor costs.

${ }^{2}$ The two extremes are captured in the minimum wage literature on one end (where studies commonly find either small positive or small negative elasticities) and the literature on city adjustments to shocks on the other (where, for example, Card (1990) finds virtually no wage response to the Mariel Boatlift supply shock in Miami).
} 
between the employment rate and the wage is the Job Creation curve, and it is the slope of this curve in which we are interested. The fact that the job creation curve relates employment rates to wages is a subtle but important difference relative to standard labor demand curves, which are often expressed as relating employment levels to wages. As we will discuss later, the search and bargaining model provides a straightforward explanation for why employment rates and employment levels can react differently to wage changes, thereby potentially accounting for some of the heterogeneity in the labor demand elasticity literature. ${ }^{3}$

The second important locus in a search and bargaining model is the wage bargaining curve. This represents the outcome of bargaining over the match specific surplus between pairs of workers and employers. It is also a relationship between the wage and the employment rate since changes in labor market tightness alter the bargaining power of workers relative to employers. The equilibrium wage and employment rate are determined by the intersection of the job creation and wage bargaining curves. Thus, we can obtain estimates of the slope of the job creation curve if we can find exogenous shifters of the wage bargaining curve such as would arise from shifts in workers' bargaining positions that are not directly related to the benefits of creating jobs. The main body of the paper is aimed at showing how and under what conditions the slope of the job creation curve can be identified with non-experimental data.

The empirical approach we use in this paper is a structural-IV approach. By this we mean that we use a structural model to carefully derive the conditions under which proposed instruments provide consistent estimates of the coefficients of interest. However, we do not directly impose the model structure on the data. Instead, we estimate relatively straightforward linear regressions using the controls and instruments indicated from the theory and then test the over-identifying restrictions that are implied by the theory. Our goal is to allow the reader to fully understand the source of variation we are using to identify parameters and its relation to the theory. We depart slightly from "full" structural estimation in that we focus on estimating only first order implications of the theory as implied by its linear approximation. We believe such a choice is desirable as it offers a simple, clear and intuitive exposition of results.

Given this approach, the theory is the central building bloc and accordingly we begin the paper by setting out a multi-sector, multi-city version of a standard search and bargaining model. In our model, local labor markets, called cities, are linked through goods trade and labor mobility. ${ }^{4}$ We extend the standard model to allow for multiple sectors as it is key for our identification strategy. Furthermore we extend the model to include heterogeneous abilities to create jobs in different industries. ${ }^{5}$ This feature is common in the firm creation literature and, in our model, provides an additional justification for a less than perfectly elastic job creation curve. Our main assumption regarding potential job creators is that they are proportional to

\footnotetext{
${ }^{3}$ For example, within our search and bargaining framework a shift in labor costs (such as arises with changes in payroll taxes) can trace out the slope of the job creation curve, while a shift in labor supply does not.

${ }^{4}$ Although labor mobility will allow expected utility to be equalized across localities, labor market frictions will nevertheless imply that wage determination maintains a local component.

${ }^{5}$ The selection mechanism implied by our entrepreneur heterogeneity approach shares similarities to other work that has modeled industries as collections of heterogeneous producers (Hamermesh (1993, Chapter 4), Jovanovic (1982), Melitz (2003)). The idea that there is heterogeneity among firms has received support from the related empirical literature (see, for example, Bartelsman and Doms (2000)).
} 
the population. ${ }^{6}$

Our empirical work is based on U.S. Census data from 1970-2000 and data from the American Community Survey for 2007. Our approach relies on comparing industry-city level changes in employment rates between localities with different levels of wage pressure due to changes in bargaining position induced by predicted shifts in industrial composition. We look at effects over periods of 10 years (except for the shorter 7 year period 2000-2007), and therefore the estimates we find are associated with quite long run phenomena.

The main idea behind our identification strategy builds on an insight from Beaudry, Green, and Sand (2009, hereafter BGS) that in a search and bargaining model with multiple sectors, a shift in the sectoral composition of the workforce toward relatively high paying sectors improves the bargaining position of all workers, even holding labor market tightness constant. This arises because a worker's outside option in bargaining with his or her employer is based on the wages the worker can obtain in alternative employment options. If, for example, a high paying steel mill closes down and is replaced by a lower paying textile mill, this affects the bargaining position of other workers in the city even if total employment has not changed. The change in bargaining positions arises because employers know that workers' wages at their outside options are now lower and so a threat to quit carries less weight. By working with data on wages and employment rates in cells defined by city and industry, we are able to take advantage of this insight. We use the theory to show that the wage bargaining curve for an industry-city unit should shift with a change in a city-level measure of industrial composition, where movements in the composition measure reflect shifts toward or away from high paying sectors. We can then identify the slope of the job creation curve in a regression of the change in the employment rate in a city-industry cell on the change in the average wage for that cell by instrumenting for the wage using predicted changes in the industrial composition index of the city. We derive the conditions under which we can obtain two valid instruments for capturing changes in the bargaining power of workers through changes in industrial composition, and we report a clear over-identification test of the validity of the assumptions. The model also has other testable implications which we assess.

The main finding of the paper is that the type of labor demand specification implied by our augmented model of search and bargaining - which emphasizes employment rate-wage trade-offs - is given substantial support in the data. In particular, the specification and overidentifying restrictions implied by theory are easily accepted. Given this, we view estimates derived from this model as a reliable basis for assessing the impact of wage changes on employment outcomes. We present estimates of two types of elasticities identified by the model. At the city level, we find an estimate -0.3, suggesting that the employment rate - labor cost trade-off is relatively inelastic. At the industry level, we find a larger elasticity, as predicted by the theory. We interpret the rather low city-level elasticity as partly reflecting a low propensity for individuals to become entrepreneurs and create jobs when wages are reduced. The model also provides a rationale for why studies focusing on regional adjustment yield results that seem to imply a very elastic labor demand curve. In particular, given a constant returns

\footnotetext{
${ }^{6}$ In a standard search and bargain model, the elasticity of the job creation curve is driven entirely by the match frictions. In our set up, this elasticity will reflect both match frictions and the potential supply of job creators. Our empirical results suggest that our proportionality assumption is a reasonable approximation.
} 
to scale matching technology and the assumption that potential job creators are proportional to the population, an exogenous inflow of workers simply replicates the economy, with no impacts wages or employment rates. We show that the data conforms to this property, which fits with other investigations of the nature of the matching function (Blanchard and Diamond, 1989). Expressed in wage/employment-level space this means that an inflow of workers traces out a flat relationship as employment expands with no effect on wages. Our interpretation implies that this flat relationship is not related to a perfectly elastic labor demand, but is instead a series of equilibrium points reflecting adjustments on both sides of the labor market.

A number of papers are related to this work. First, we build on standard equilibrium search models (Pissarides, 2000) to include endogenous industrial composition (Acemoglu, 1999, 2001). In contrast to these latter studies, which are mainly theoretical and focus on factors that influence the composition of jobs, the primary focus of this paper is empirical and investigates the long-run consequences of industrial composition for wage and employment outcomes. This focus also differentiates our work from studies of regional adjustment to aggregate labor demand changes (Blanchard and Katz, 1992; Bartik, 1993, 2006). Our paper is also related to work investigating the impact of labor costs on employment, as surveyed by Blau and Kahn (1999), and to a large literature examining local adjustment to supply shocks (see, for example, Lewis (2004), Boustan, Fishback, and Kantor (2007) and Card (2009), among others), and concerned with issues similar to Krueger and Pischke (1997). Our work is different from all of these studies because it is based on an empirical evaluation of a search and bargaining model and, therefore, we offer an different interpretation of the data. Our empirical findings are, nonetheless, largely consistent with the main empirical observations highlighted in these literatures.

The remaining sections of the paper are as follows. In section 1 we propose an extended search and bargaining model and illustrate the implications of such a model for an empirical specification of a job creation curve. In particular, we use the model to derive both an empirical specification and an instrumental variable strategy for identifying key parameters. In section 2 , we present our data and discuss implementation issues. In section 3 , we present a large set of results. The model we derive implies a number of estimating strategies and we illustrate how the results from each reinforces the other by satisfying various constraints in the data that are implied by theory. In section 4 we assess the robustness of our results. Section 5 concludes.

\section{Theoretical Framework}

In this section, we set out an extended version of a standard search and bargaining model which incorporates multiple sectors, multiple cities, and limited entrepreneurial talent. Our goal is to derive an empirical specification of the job creation curve and show how such a job creation curve can be estimated with city-level data. Because of that goal, our model is highly stylized, but we will show that it still yields strong testable implications, which will allow us

to evaluate whether such a simple model is a reasonable approximation of the data generating 
process. ${ }^{7}$

We consider an economy in which there is one final good, $Y$, which is an aggregation of output from $I$ industries:

$$
Y=\left(\sum_{i=1}^{I} a_{i} Z_{i}^{\chi}\right)^{1 / \chi}, \quad \text { where } \chi<1
$$

The price of the good, $Y$, is normalized to 1 and the price of good $i$ is given by $p_{i}$. There are $C$ local markets, or cities, and the "I" industry goods can be produced in any of these markets. The total quantity of good $i, Z_{i}$, equals the sum across cities of $X_{i c}$, the output in industry $i$ in city $c$.

\subsection{Search}

We assume that search frictions characterize the labor markets in all cities and focus on the steady-state. Initially, we will concentrate on the somewhat extreme case in which workers are not mobile across cities. However, as we will see in a later section, the results derived here are robust to including worker mobility and allowing housing prices to adjust such that the expected utility across cities is equalized.

Each local economy unfolds in continuous time and consists of firms and workers who are risk neutral, infinitely lived, and discount the future at a rate, $\rho$. Firms and workers come together in pairs according to a matching technology and matches end at an exogenous rate, $\delta$. Define $L_{c}$ as the total available number of workers in city $c$, and $E_{i c}$ and $N_{i c}$ as the number of employed workers (or matches), and the number of available jobs in industry $i$ in city $c$, respectively, and $E_{c}=\sum_{i} E_{i c}$ and $N_{c}=\sum_{i} N_{i c}$. The number of matches produced per unit of time is governed by the matching function:

$$
M=M\left(\left(L_{c}-E_{c}\right),\left(N_{c}-E_{c}\right)\right),
$$

where the inputs are the available pool of unemployed workers, $L_{c}-E_{c}$, and the number of vacancies, $N_{c}-E_{c}$. As is standard in the search and bargaining literature, we assume the matching technology exhibits constant returns to scale and is increasing in both arguments. We test the constant returns to scale assumption in our empirical work.

These properties of the matching technology imply that we can write the probability that a worker encounters a vacancy and the probability a firm fills a vacancy as:

$$
\psi_{c}=\frac{M\left(\left(L_{c}-E_{c}\right),\left(N_{c}-E_{c}\right)\right)}{L_{c}-E_{c}} \quad \text { and } \quad \phi_{c}=\frac{M\left(\left(L_{c}-E_{c}\right),\left(N_{c}-E_{c}\right)\right)}{N_{c}-E_{c}},
$$

respectively. In steady state, the flow of workers leaving unemployment must equal the flow of workers exiting employment, implying the equilibrium condition:

$$
\delta \frac{E_{c}}{L_{c}}=M\left(1-\frac{E_{c}}{L_{c}}, \frac{N_{c}}{L_{c}}-\frac{E_{c}}{L_{c}}\right) .
$$

\footnotetext{
${ }^{7}$ Our model exposition shares much with that in BGS but the model in that paper emphasizes the wage bargaining curve while here we focus on the derivation of the job creation curve.
} 


\subsection{Bellman Equations}

Firms can open jobs in any industry and city. To create a job in industry $i$ in city $c$, a firm must pay a cost, $k_{i c}$, the value of which will be determined in equilibrium. Denote by $V_{i c}^{v}$ the present-discounted value of a vacancy in industry $i$ and city $c$. In steady-state, $V_{i c}^{v}$ must satisfy the Bellman equation:

$$
\rho V_{i c}^{v}=-r_{i}+\phi_{c}\left(V_{i c}^{f}-V_{i c}^{v}\right),
$$

where $r_{i}$ is the flow cost of maintaining the vacancy and with probability $\phi_{c}$ the vacancy is converted into a filled job, which has a present-discounted value of $V_{i c}^{f}$. In equilibrium, this value must satisfy

$$
\rho V_{i c}^{f}=p_{i}-w_{i c}+\epsilon_{i c}+\delta\left(V_{i c}^{v}-V_{i c}^{f}\right),
$$

where $p_{i}$ is the price of the industrial good, $w_{i c}$ the wage paid to workers in industry $i$ in city $c$, and $\epsilon_{i c}$ is an industry-city cost advantage where we assume $\sum_{c} \epsilon_{i c}=0$. Thus, once a match occurs, a firm enjoys a profit flow of $p_{i}-w_{i c}+\epsilon_{i c}$, and with probability $\delta$ the match is broken.

Workers can either be employed or unemployed. Denote the present-discounted value of employment and unemployment in industry $i$ in city $c$ as $U_{i c}^{e}$ and $U_{i c}^{u}$, respectively. The value of $U_{i c}^{e}$ in steady-state must satisfy the Bellman relationship:

$$
\rho U_{i c}^{e}=w_{i c}+\delta\left(U_{i c}^{u}-U_{i c}^{e}\right),
$$

where $w_{i c}$ is the wage paid to the worker in industry $i$ in city $c$. When an individual is unemployed, he receives a flow utility from an unemployment benefit, $b$, plus a city-specific amenity, $\tau_{c}$, that can be interpreted as the difference in flow utility associated with amenities when unemployed versus when someone is employed. The probability that a potential worker finds a job is $\psi_{c}$. Let $\mu$ denote the probability that an individual is matched with his previous industry, and $1-\mu$ the probability that he draws a job from all industries (including $i$ ). Thus, the value of unemployment must satisfy:

$$
\rho U_{i c}^{u}=b+\tau_{c}+\psi_{c}\left(\mu \cdot U_{i c}^{e}+(1-\mu) \cdot \sum_{j} \eta_{j c} U_{j c}^{e}-U_{i c}^{u}\right) .
$$

The important aspect of equation (8) is that, as long as $\mu<1$, the utility level associated with having lost one's job in industry $i$ depends on the utility associated with jobs in other industries. The instantaneous probability of finding a job in industry $j$ is given by $\psi_{c} \cdot(1-\mu) \cdot \eta_{j c}$, where $\eta_{j c}$ represents the fraction of vacant jobs that are in industry $j$. This implies that a worker finding a job in another industry is assumed to find it in proportion to the relative size of that industry. ${ }^{8}$

In writing the above equations, we have assumed that there are always gains from trade between workers and firms in all jobs created in equilibrium. Once a match is made, workers and firms bargain a wage, which is set according to the bargaining rule:

$$
\left(V_{i c}^{f}-V_{i c}^{v}\right)=\left(U_{i c}^{e}-U_{i c}^{u}\right) \cdot \kappa,
$$

\footnotetext{
${ }^{8}$ We are assuming that workers can only search while being unemployed. While this is a strong assumption, we maintain it throughout since it has the attractive feature of allowing the problem to be solved explicitly for simple empirical specifications.
} 
where $\kappa$ is a parameter governing the relative bargaining power of workers and firms. Finally, the number of jobs created in industry $i$ in city $c, N_{i c}$, is determined by the free entry condition:

$$
k_{i c}=V_{i c}^{v}
$$

The cost $k_{i c}$ should be viewed as the cost of creating a marginal job. If this cost were fixed, then cities would generally specialize in only one industry. Since we want to generate cities with employment across a wide range of industries, we model $k_{i c}$ as increasing in the number of new jobs being created locally in that industry. To do this, we model the supply of jobs as being determined by the decisions of a set of potential job creators who differ in terms of set-up costs. In particular, we assume that in each period, an individual in city c (in addition to being a worker) receives the option of creating a job in industry $i$ with probability $\tilde{\Omega}_{i c}$. He then learns his cost of creating a job, which is drawn from the distribution $f(\cdot)$. Since the expected value of creating a job in industry $i$ in city $c$ is $V_{i c}^{v}$, all jobs with costs lower than $V_{i c}^{v}$ will be undertaken. Therefore, the number of jobs created in industry $i$ in city $c$ in a period, denoted $J_{i c}$, will be

$$
J_{i c}=L_{c} \cdot \tilde{\Omega}_{i c} \cdot F\left(V_{i c}^{v}\right)
$$

where $F(\cdot)$ is the CDF associated with $f(\cdot)$. In the steady state equilibrium, the number of jobs created every period will need to equal to the number of jobs destroyed. Given that $E_{i c}$ represent the level of employment in the industry-city cell, the marginal cost of creating a job can then be expressed as

$$
F^{-1}\left(\frac{\delta E_{i c}}{L_{c} \cdot \tilde{\Omega}_{i c}}\right)=k_{i c}
$$

where $\tilde{\Omega}_{i c}$ can be interpreted as a city-industry comparative advantage in creating certain types of jobs. It will be convenient to decompose this advantage into two terms: $\tilde{\Omega}_{i c}=\Omega_{i}+\Omega_{i c}$, where $\Omega_{i}$ represents an industry effect that reflects systematic job creation probabilities for industries that is common to all cities, and $\Omega_{i c}$ reflects a city-industry component with the property that $\sum_{c} \Omega_{i c}=0$.

This formulation implies that lower cost entrepreneurs enter the market and create jobs first. If employment is to expand, the value of creating jobs must rise in order to maintain zero profits for the marginal entrepreneur who is of increasingly lower quality. This has the effect in our model of providing an additional reason for a less than perfectly elastic job creation curve because the supply of potential job creators is negatively related to wages (positively related to the value of a vacancy, $V_{i c}^{v}$.). This relationship is what we mean when we refer to limited entrepreneurial talent: at any given wage, only a subset of potential job creators will find it profitable to create jobs.

\subsection{Model Solution}

At the city level, prices of industrial goods are taken as given and an equilibrium is defined by values of $N_{i c}, w_{i c}$, and $\frac{E_{c}}{L_{c}}$ such that equations (4) through (10) are satisfied. At the economywide level, prices adjust to ensure that markets for industrial goods clear. Price changes 
occur when there are shifts in demand for industrial goods, captured in the model by the $a_{i}$ parameters. Local outcomes respond to industry prices and local advantages, captured by the $\Omega_{i c} \mathrm{~s}$ and $\epsilon_{i c} \mathrm{~s}$. We will take the above description of a steady-state equilibrium as representing an equilibrium at a point in time and examine how this equilibrium changes in response to changes in the exogenous driving forces, $a_{i}, \Omega_{i c}$, and $\epsilon_{i c}$. We develop our empirical strategy by focusing the difference between two steady-state relationships.

\subsubsection{Job Creation}

Using equations (5) and (6), we can write the value of a vacancy as:

$$
\rho V_{i c}^{v}=\alpha_{c 1} \cdot r_{i}+\alpha_{c 2} \cdot\left(p_{i}-w_{i c}+\epsilon_{i c}\right),
$$

where $\alpha_{c 1}=-\frac{(\rho+\delta)}{\rho+\delta+\phi_{c}}$ and $\alpha_{c 2}=\frac{\phi_{c}}{\rho+\delta+\phi_{c}}$. Note that both $\alpha_{c 1}$ and $\alpha_{c 2}$ depend on a city's vacancy contact rates, $\phi_{c}$, which, in turn, depend on the city's employment rate, $\frac{E_{c}}{L_{c}}$. It is useful to make this relationship explicit by taking a linear approximation around the point where cities have an identical employment rate and industrial composition (this arises when cities have $\epsilon_{i c}=0$, and $\Omega_{i c}=0$ ). In addition, for reasons we will make clear shortly, it will be useful to work in log changes between two periods. We can then rewrite (13) using a log-linear approximation as:

$$
\Delta \ln V_{i c t}^{v}=\tilde{\alpha}_{i t}+\alpha_{2} \Delta \ln w_{i c t}+\alpha_{3} \Delta \ln \frac{E_{c t}}{L_{c t}}+\alpha_{4} \Delta \epsilon_{i c t}
$$

where $\Delta x_{i t}=x_{i t}-x_{i t-1}$ and we have added time subscripts because we will use data from several periods. The $\tilde{\alpha}_{i t}$ s correspond to industry-year specific effects, and, hence, can be captured in an empirical specification by industry-year dummy variables. The coefficients $\alpha_{2}$ and $\alpha_{3}$ (which are evaluated at common vacancy filling rates) are predicted to be negative since, all else equal, the return to opening new jobs will be lower when wages are higher and when the labor market is tighter (implying a longer time to fill a vacancy). The last term represents an error term that depends on the city-industry cost advantages.

We now want to relate the change in the value of a vacancy with the employment rate in an industry. To this end, we can use (12), log-linearizing it and taking differences between two periods, to arrive at:

$$
\Delta \ln k_{i c t}=\theta_{1} \Delta \ln \frac{E_{i c t}}{L_{c t}}+\theta_{2} \Delta \tilde{\Omega}_{i c t}
$$

where $\theta_{1}$ is a positive coefficients which reflects that marginal set-up costs increase (or average entrepreneur quality declines) as employment expands in a city, and $\theta_{2}$ is a negative coefficient that reflects the impact of increasing the size of the pool of potential job creators on $\Delta \ln k_{i c t}$.

Finally, we can use the entry condition, (10), to equate equations (14) and (15) to give us an empirical specification for job creation:

$$
\Delta \ln \frac{E_{i c t}}{L_{c t}}=\varphi_{i t}+\varphi_{2} \Delta \ln w_{i c t}+\varphi_{3} \Delta \ln \frac{E_{c t}}{L_{c t}}+\zeta_{i c t}
$$

where the $\varphi_{i t}$ represent a set of common industry-year effects, and $\varphi_{2}=\frac{\alpha_{2}}{\theta_{1}}<0$ is the elasticity of labor demand with respect to wages holding the aggregate employment rate constant. Note 
that this elasticity is decreasing in $\theta_{1}$. This arises due to the fact that although lower wages increase the profitability of job creation less individuals will choose to create more jobs if $\theta_{1}$ is high. Hence, in this model, one of the reason that the elasticity of employment with respect to wages can be low is that the supply of entrepreneurial activity may have a low elasticity relative to variable profits. The more common assumption in the search and bargaining literature is to assume that the cost of creating jobs is constant (often zero), and therefore $\theta_{1}$ is implicitly zero with the implication that labor demand should be infinitely elastic. By estimating equation 16 we will be able to examine whether such an approximation is appropriate. The last term in (16), $\zeta_{i c}=\frac{1}{\theta_{1}}\left(\alpha_{4} \Delta \epsilon_{i c}-\theta_{2} \Delta \Omega_{i c}\right)$, is an error term that depends on city variable costs and job creation advantages.

Equation (16) forms the basis of our empirical investigation and can be interpreted as a Job Creation curve at the city-industry level. Notice that the equation involves a reflection problem (Manski, 1993; Moffitt, 2001). To see this, note that $\Delta \ln \frac{E_{c t}}{L_{c t}}$ can be approximated by $\sum_{i} \eta_{i c t} \Delta \ln \frac{E_{i c t}}{L_{c t}}$ so that (16) involves a regression of the change in the log employment rate in a given city-industry cell, $\Delta \ln \frac{E_{i c}}{L_{c}}$, on its average across such cells within a city. We could address this issue directly via an instrument or solve out for $\Delta \ln \frac{E_{c t}}{L_{c t}}$. We implement both approaches in our empirical work. However, this will not solve all of the simultaneity problems inherent in (16), since within-industry wage changes, $\Delta \ln w_{i c t}$, are simultaneously determined with $\Delta \ln \frac{E_{i c}}{L_{c}}$ in the model and, as we show in the following section, are also a function of the city-wide employment rate. Thus, to consistently estimate (16), we must identify variation in wages that is uncorrelated with $\Delta \epsilon_{i c}$ and $\Delta \Omega_{i c}$ in the error term in (16) and that is separate from variation in the city employment rate. The following section discusses the wage determination process in the search and bargaining model and illustrates our procedure for dealing with the simultaneity issues.

\subsubsection{Determination of Wages}

Using equations (5) and (6), we can derive an expression for $V_{i c}^{f}-V_{i c}^{v}$. Similarly, equations (7) and (8) can be used to derive an expression for $U_{i c}^{e}-U_{i c}^{u}$. Using these expressions along with the bargaining equation (9), we can write the following wage equation: ${ }^{9}$

$$
w_{i c}=\gamma_{c 0}+\gamma_{c 1} p_{i}+\gamma_{c 2} \sum_{j} \eta_{j c} w_{j c}+\gamma_{c 1} \epsilon_{i c} .
$$

Equation (17) links wages in industry $i$ in city $c$ to the national price of the industrial good, $p_{i}$, and the average level of wages in city $c{ }^{10}$ Equation (17) captures the notion that in a multi-sector search and bargaining model sectoral wages act as strategic complements; that is, high wages in one sector are associated with high wages in other sectors. This follows directly from a combination of equations (7) and (8), which show that a worker's outside option in bargaining depends on the wages he could get at other jobs in the city weighted by the probabilities of getting those jobs. The intercept, $\gamma_{c 0}$, is a function of unemployment benefits, $b$.

${ }^{9}$ This section is a much shortened version of the discussion in BGS. Thus, BGS can be seen as an extended investigation of the first stage in the estimation of the job creation curve in this paper.

${ }^{10}$ The coefficients in (17) are $\gamma_{c 0}=\frac{\left(\rho+\delta+\psi_{c} \mu\right)\left(\rho+\delta+\phi_{c}\right) \kappa}{\left[\left(\rho+\delta+\psi_{c} \mu\right)+\kappa\left(\rho+\delta+\phi_{c}\right)\right]\left(\rho+\delta+\psi_{c}\right)}\left(b+\tau_{c}\right), \gamma_{c 1}=\frac{\rho+\delta+\psi_{c} \mu}{\left(\rho+\delta+\phi_{c}\right) \kappa+\left(\rho+\delta+\psi_{c} \mu\right)}$ and $\gamma_{c 2}=$ $\frac{\left(\rho+\delta+\phi_{c}\right) \kappa}{\left[\left(\rho+\delta+\psi_{c} \mu\right)+\kappa\left(\rho+\delta+\phi_{c}\right)\right]} \frac{\psi_{c}(1-\mu)}{\left(\rho+\delta+\psi_{c}\right)}$. See BGS for additional details on deriving this expression. 
Thus, (17) reflects the standard search model result that wages are a function of productivity $\left(p_{i}+\epsilon_{i c}\right)$ and the value of a worker's outside option (which is, in turn, a function of $b$ and the wage he would expect to earn in other sectors in the city).

The wage equation, (17), again contains a classic reflection problem in that the sectoral wage depends on the average of such wages in the city. One can respond to this, in part, by using the model to show that the average wage can be replaced by $\sum_{j} \eta_{j c} w_{j c}$, which is a function of national level wage premia. In particular, through a series of simple derivations, we can rewrite the wage equation (17) as

$$
w_{i c}=\tilde{d}_{i c}+\left(\frac{\gamma_{c 2}}{1-\gamma_{c 2}}\right)\left(\frac{\gamma_{c 1}}{\gamma_{1}}\right) \sum_{j} \eta_{j c} \nu_{j}+\gamma_{c 1} \epsilon_{i c}+\gamma_{c 1}\left(\frac{\gamma_{c 2}}{1-\gamma_{c 2}}\right) \sum_{j} \eta_{j c} \epsilon_{j c}
$$

where, $\nu_{i}=w_{i}-w_{1}$ (the wage premium relative to an arbitrary baseline industry, 1 , at the national level), and $\tilde{d}_{i c}$ is a function of $\gamma_{c 0}, \gamma_{c 1}, \gamma_{c 2}$ from equation (17) as well as $p_{i}$. We refer the reader to BGS for the derivation linking (17) to (18) but note that the $\gamma$ coefficients are functions of $\phi_{c}$ and, therefore, of the city-level employment rate.

Equation (18) states that wages within an industry-city cell depend on the industrial composition of a city as captured by the index $\sum_{j} \eta_{j c}\left(w_{i}-w_{1}\right)$. We will denote this index by $R_{c}$ and refer to it as average city rent. A high value of this index indicates that a city's employment is concentrated in high paying industries. Thus, the specific composition effect captured in (18) is one related to the proportion of "good jobs" in a city, where by good jobs we mean jobs in industries that pay a relative wage premium. ${ }^{11}$

As with the job creation curve, it is useful to make the dependence of wages on the city's employment rate more explicit by taking a linear approximation of (18) under the same conditions that were used to derive equation (13). Furthermore, to eliminate the city-level fixed effects driven by the amenity, $\tau$, we focus on the difference in wages within a city-industry cell across two steady state equilibria, denoted $\Delta w_{i c}$. This is given by equation (19):

$$
\Delta w_{i c}=\Delta d_{i}+\left(\frac{\gamma_{2}}{1-\gamma_{2}}\right) \Delta \sum_{j} \eta_{j c} \nu_{i}+\gamma_{5} \Delta \frac{E_{c}}{L_{c}}+\Delta \xi_{i c}
$$

where: $\Delta d_{i}$ is an industry-specific effect incorporating $\Delta p_{i}$ that does not vary across cities, and hence can be captured in an empirical specification by including industry dummies; and $\Delta \xi_{i c}=\gamma_{1} \Delta \epsilon_{i c}+\gamma_{1} \frac{\gamma_{2}}{1-\gamma_{2}} \sum_{j} \frac{1}{I} \Delta \epsilon_{j c}$ is the error term, with $I$ being the total number of industries. ${ }^{12}$ The added coefficient, $\gamma_{5}$, reflects the effect of a change in the employment rate on wage determination; an effect which depends on all the parameters of the model.

To obtain our final equation for wages, we divide both sides of (19) by $w_{1}$ in order to focus on a log specification and re-introduce time subscripts since we will pull data from different periods:

$$
\Delta \ln w_{i c t}=d_{i t}+\beta_{2} \Delta R_{c t}+\beta_{3} \Delta \ln \frac{E_{c t}}{L_{c t}}+\Delta \xi_{i c t}
$$

\footnotetext{
${ }^{11}$ It is important that these wage differentials are rents since if they just reflect compensating differentials or industry specific skills then workers in other industries could not use them as the basis for bargaining for a better wage.

${ }^{12}$ In (19), the $\gamma$ coefficients are the same as presented after equation (17), except now they are evaluated at common match probabilities, $\psi$ and $\phi$.
} 
where the $d_{i t}$ S are time-varying industry effects, $\beta_{2}=\frac{\gamma_{2}}{1-\gamma_{2}}$ gives the impact of a change in industrial composition on wages, $R_{c t}=\sum_{i} \eta_{i c}\left(\frac{w_{i}}{w_{1}}-1\right)$ is our index of industrial composition, $\beta_{3}=\frac{\gamma_{5}}{w_{1}} \frac{E}{L}$ is the coefficient capturing the effect of city-level employment rates on wages, and $\Delta \xi_{i c t}$ is the error term defined by $\Delta \xi_{i c t}=\frac{\gamma_{1}}{w_{1}} \Delta \epsilon_{i c t}+\frac{\gamma_{1}}{w_{1}} \frac{\gamma_{2}}{1-\gamma_{2}} \sum_{j} \frac{1}{I} \Delta \epsilon_{j c t}$.

\subsection{Dealing with Endogeneity}

The wage equation (20) developed in the previous section highlights the difficulties in identifying the parameters in the job creation equation (16). In particular, with $\Delta \ln w_{i c t}$ on the right hand side of (16) and local productivity shocks $\epsilon_{i c t} \mathrm{~s}$ appearing in the error terms for both $\Delta \ln w_{i c t}$ and $\Delta \ln \frac{E_{i c t}}{L_{c t}}$, we face a standard endogeneity problem. At first glance, the derivation of the wage and job creation equations in a multi-sector context also suggests a potential instrument: $\Delta R_{c t}$, the change in industrial composition, affects $\Delta \ln w_{i c t}$ through its impact on bargaining positions but affects $\Delta \ln \frac{E_{i c t}}{L_{c t}}$ only indirectly, through its impact on wages. As described earlier, estimating equation (16) also involves solving a reflection problem. We return to that problem below.

While $\Delta R_{c t}$ may appear at first to be a good candidate as an instrument, there are obvious reasons to question its validity. In particular, $\Delta R_{c t}$ is itself endogenous since it is a function of the $\eta \mathbf{s}$ (the industry shares), the $\eta \mathbf{s}$ can be written as functions of the $\epsilon \mathrm{s}$ and $\Omega \mathrm{s}$ (the local productivity shocks and cost advantages), and the $\epsilon \mathrm{S}$ and $\Omega \mathrm{s}$ are present in the error term of equation (16). Given this, instead we will propose two instruments that are based in part on national-level variation in employment and wages, and we will show under what conditions they are valid. Our proposed instruments are related to the two components in a standard decomposition of $\Delta R_{c t}$ given by, $\Delta R_{c t}=\sum_{i}\left(\eta_{i c t}-\eta_{i c t-1}\right) \cdot \nu_{i t-1}+\sum_{i} \eta_{i c t} \cdot\left(\nu_{i t}-\nu_{i c t-1}\right)$.

To create our first instrument, we first predicting the level of employment for industry $i$ in city $c$ in period $t$ as:

$$
\hat{E}_{i c t}=E_{i c t-1}\left(\frac{E_{i t}}{E_{i t-1}}\right) .
$$

Thus, we predict period $t$ employment in industry $i$ in city $c$ using the employment in that industry-city cell in period $t-1$ multiplied by the national level growth rate for the industry. We then use these predicted values to construct predicted industry specific employment shares, $\hat{\eta}_{i c t}=\frac{\hat{E}_{i c t}}{\sum_{i} \hat{E}_{i c t}}$, for the city in period $t$ and, finally, form our first instrument as,

$$
I V 1_{c t}=\sum_{i} \nu_{i t-1} \cdot\left(\hat{\eta}_{i c t}-\eta_{i c t-1}\right)
$$

This instrument is closely related to the first component of the decomposition of $\Delta R_{c t}$ : the component relating just to changes in the employment composition. By using predicted changes in employment shares based on national-level employment growth, the instrument breaks the direct connection between growth in wages and growth in employment at the industry-city level.

Our second instrument relates to the second component in the variation of $\Delta R_{c t}$ which reflects changes in national wage premia over time. Those national level changes are weighted 
by the share of the relevant industry in the city at the start of the period. Thus, our second instrument is,

$$
I V 2_{c t}=\sum_{i} \hat{\eta}_{i c t} \cdot\left(\nu_{i t}-\nu_{i t-1}\right)
$$

For $I V 1_{c t}$ to be a valid instrument we require (along with it being a significant determinant of wages and the assumption that it does not belong in (16)):

$$
\lim _{C, I \rightarrow \infty} \frac{1}{I} \frac{1}{C} \sum_{i=1}^{I} \sum_{c=1}^{C} I V 1_{c t} \zeta_{i c t}=\lim _{C, I \rightarrow \infty} \frac{1}{I} \frac{1}{C} \sum_{c=1}^{C} I V 1_{c t} \sum_{i=1}^{I} \zeta_{i c t}=0,
$$

where $\zeta_{i c t}=\frac{1}{\theta_{1}} \cdot\left(\alpha_{4} \Delta \epsilon_{i c t}-\theta_{2} \Delta \Omega_{i c t}\right)$, the error term in (16). ${ }^{13}$ The conditions under which this condition are met are best understood by re-stating $\epsilon_{i c}$ (and $\Omega_{i c}$, as well) as the sum of a common city component (or absolute advantage component) and a second, relative advantage component. Thus, denote $\hat{\epsilon}_{c t}$ and $\hat{\Omega}_{c t}$ as the common components of the $\epsilon \mathrm{s}$ and the $\Omega \mathrm{s}$, respectively, and let $v_{i c t}^{\epsilon}$ and $v_{i c t}^{\Omega}$ represent the relative advantage components. Then, $\epsilon_{i c t} \equiv \hat{\epsilon}_{c t}+v_{i c t}^{\epsilon}$ and, by definition, the $v_{i c t}^{\epsilon} \mathrm{s}$ across industries within a city sum to zero (with similar expressions for $\left.\Omega_{i c t}\right)$. Both $I V 1_{c t}$ and $I V 2_{c t}$ are functions of the relative error components, $v_{i c t-1}^{\epsilon}$, but not of the common error component. In contrast, $\sum_{i=1}^{I} \zeta_{i c t}$ depends only on the absolute advantage component of the $\epsilon \mathrm{S}$ and $\Omega \mathrm{S}$ (since the $v_{i c t}^{\epsilon} \mathrm{S}$ sum to zero). As a result, as we show in Appendix A, these instruments provide consistent estimates under the condition that $\Delta \hat{\epsilon}_{c}$ and $\Delta \hat{\Omega}_{c}$ are independent of $v_{i c t-1}^{\epsilon}$ and $v_{i c t-1}^{\Omega}$; i.e., that changes in the absolute advantage of a city are independent of the past level of comparative advantage for the various industries in a city. Note that this allows for the possibility that a city that shifts in the direction of a higher wage industrial composition also experiences general improvements in cost advantages. We just require that those general improvements not be systematically predictable based on past aspects of comparative advantage.

The use of $I V 1_{c t}$ and $I V 2_{c t}$ provides an over-identification test for the model. The two instruments represent substantially different forms of variation, with one based on movements in national-level employment growth and the other on movements in national-level wage premia. In fact, in our Census data, described in section 2, their correlation (after removing year effects as we do in all of our estimations), is only 0.18. Yet, the model indicates that both types of variation should have the same effect on wages and, through them, on employment rates since what matters for a workers bargaining position is the change in the average wage in other industries, regardless of whether that change stems from changes in industrial composition or the industrial wage premia. Thus, a standard over-identification test represents a strong test of the model and the assumption under which the instruments are valid. As with all such tests, it is not impossible that an alternative model would imply the same test statistic but we have not been able to discern what such a model would look like, while the restriction is a clear implication of a search and bargaining model.

\subsubsection{Endogeneity of Employment Rates}

The last endogeneity issue relates to the potential correlation between the change in the employment rate, $\Delta \ln \frac{E_{c}}{L_{c}}$, and the error term in (16) arising from the fact that $\Delta \ln \frac{E_{c}}{L_{c}}$ is

\footnotetext{
${ }^{13} \mathrm{An}$ analogous condition is required for $I V 2_{c t}$ to be a valid instrument.
} 
an aggregation of the dependent variable in (16). Our first response that problem is to use an instrument that is similar to $I V 1$ and similar to the one used in Blanchard and Katz 1992. In particular, we use as an instrument $\sum_{i} \eta_{i c t-1} g_{i t}$, where $g_{i t}$ is the growth rate of employment in industry $i$ at the national level. Thus, the instrument is the weighted average of nationallevel industrial employment growth rates, where the weights are the start of period industrial employment shares in the local economy. A city that has a strong weight on an industry that turns out to grow well at the national level will have a high value for this instrument. Because the $\epsilon_{i c} \mathrm{~s}$ that drive the error term are local demand shocks that sum to zero across cities, their movements are not correlated with the $g_{i t}$ s by construction. Finally, under the assumption that $\Delta \epsilon_{i c t}$ is independent of $v_{i c t}^{\epsilon}$, the changes in $\epsilon_{i c t}$ that constitute $\zeta_{i c t}$ will be independent of the $\eta_{i c t-1} \mathrm{~s}$ used as weights in the instrument, resulting in a zero correlation between the instrument and the error term.

We can also respond to the reflection problem inherent in (16) by forming a consistent expression for $\Delta \ln \frac{E_{c}}{L_{c}}$ as a function of other variables in the model and substituting it in for $\Delta \ln \frac{E_{c}}{L_{c}}$. We will also pursue that approach in section (3).

\subsection{Worker Heterogeneity}

As we have indicated, our aim in this paper is to provide an estimate of how employment, on average, is affected by an across-the-board increase in the cost of labor. By its very nature, this question is about an aggregate labor market outcome. In the model developed so far all workers are identical and so all paramters are "aggregate" by definition. However, in our data, workers are heterogeneous in, for example, education and experience. We need to address this heterogeneity in order to provide a consistent answer to our aggregate question. Depending on the assumptions that one makes, there are several ways to approach this issue.

Our first approach, which we use for our main set of results, is to treat individuals as potentially representing different bundles of efficiency units of work, where these bundles are treated as perfect substitutes in production. Therefore, we control for skill differences in wages via a regression adjustment. However, the theory indicates that we should not account for differences in worker attributes when aggregating the number of workers across industries and cities in the calculation of employment rates. In Appendix C, we present a formal justification for such an approach. Heuristically, the structure of the basic search model allows one to write the wage of any skill type in reference to the wage of some arbitrary type, which rationalizes the use of the regression adjusted wages. In addition, random matching implies that the probability of meeting a worker of a given skill type will equal the product of the vacancy filling rate and the proportion of that worker's type in the local economy. Thus, the effects of labor market tightness and skill can be separated and, we argue in the appendix, that the latter effects can be expected to be relatively small. Hence, the value of a vacancy will depend on the skill distribution of the workforce in general, but it is probably only of second-order importance. Our approach is to ignore these additional effects in our baseline specification. However, in the robustness section we will show that our results are not sensitive to controlling for measures of the aggregate distribution of skill in a locality.

An alternative assumption is that labor markets are segregated along observable skill dimensions and that our model applies to homogeneous workers within these markets. Thus, 
we also perform our analysis separately by education group as a specification check. Finally, if one assumes that the matching function is not over workers but over efficiency units then it is appropriate when aggregating workers over industries and cities to use efficiency weighted worker counts. When we construct our employment variables in this manner it does not substantially affect our main results. However, we choose not to pursue this interpretation as it appears quite artificial in the search bargaining context. Nonetheless, results using efficiency units are available by request.

\subsection{Mobility}

The model presented above assumes that workers are not mobile across localities. It may seem, at first, that allowing for worker mobility could overturn the result that wages differ across localities because of local bargaining conditions. However, this will not generally be the case, even when we allow for directed search across cities. In Appendix D, we offer two extensions of the model that take into account worker mobility. In the first extension, unemployed workers are not perfectly mobile, but are only occasionally offered the opportunity to switch cities. Because of this friction, wages (and outside options) will maintain a local component. When the option to switch cities arises, workers choose the city that maximizes the value of their search. Since this choice will not depend on the initial location of the worker, it acts as a common element across workers and is captured by an intercept. ${ }^{14}$ In this extension of the model, none of our empirical specifications are affected and the model's implications will continue to hold.

In the second extension, we go further by modeling more explicitly the spacial equilibrium. In particular, we introduce local housing prices and allow workers to choose a city that maximizes expected utility, taking into account housing costs and local amenities. In this extension, we modify workers' Bellman equations, (8) and (7), to include a negative function of the local housing price. Importantly, housing prices will not directly affect wage negotiation because it is a cost that is incurred whether or not an individual is employed (and wages depend on the difference $\left.U_{i c}^{e}-U_{i c}^{u}\right)$. However, housing prices will have to adjust to equilibrate expected utility across cities. In Appendix D, we present this simple model with housing costs that depend positively on local amenities and city size. We show that it implies that a city with a higher employment rate or a higher expected wages (i.e., due to higher values of $R_{c t}$ ) will attract more workers. This in-migration will drive up local housing costs to the point where expected utility is equalized across cities, but in-migration will stop before wage equalization occurs. Thus, the forces we emphasize in our model also have implications for worker mobility and housing costs. Toward the end of the paper, we present results which support this mechansim.

\section{Data Description and Implementation Issues}

The data we use in this paper come from the U.S. decennial Censuses from the years 1970 to 2000 and from the American Community Survey (ACS) for 2007. For the 1970 Census data,

\footnotetext{
${ }^{14}$ Random search across cities has the same implication.
} 
we use both metro sample Forms 1 and 2 and adjust the weights for the fact that we combine two samples. ${ }^{15}$ We focus on individuals residing in one of our 152 metropolitan areas at the time of the Census. Census definitions of metropolitan areas are not comparable over time. The definition of cities that we use in this paper attempts to maximize geographic consistency across Census years. Since most of our analysis takes place at the city-industry level, we also require a consistent definition of industry affiliation. Details on how we construct the industry and city definitions are left to Appendix B.

As discussed earlier, our approach to dealing with worker heterogeneity is to control for observed characteristics in a regression context. Since most of our analysis takes place at the city-industry level, we use a common two-step procedure. Specifically, using a national sample of individuals, we run regressions separately by year of log weekly wages on a vector of individual characteristics and a full set of city-by-industry dummy variables. ${ }^{16}$ We then take the estimated coefficients on the city-by-industry dummies as our measure of city-industry average wages, eliminating all cells with fewer than 20 observations.

Our interpretation of the regression adjusted wage measure is that it represents the wage paid to workers for a fixed set of skills. However, since we only observe the wage of a worker in city $j$ if that worker chooses to live and work in $j$, self-selection of workers across cities may imply that average city wages are correlated with unobserved worker characteristics such as ability. In this case, our wage measure will not represent the wage paid per efficiency unit but will also reflect (unobservable) skill differences of workers across cities. To address this potential concern, when we estimate our wage equations we control for worker self-selection across cities with a procedure developed and implemented by Dahl (2002) in a closely related context.

Dahl proposes a two-step procedure in which one first estimates various location choice probabilities for individuals, given their characteristics such as birth state. In the second step, flexible functions of the estimated probabilities are included in the wage equation to control for the non-random location choice of workers. ${ }^{17}$ The actual procedure that we use is an extension of Dahl's approach to account for the fact we are concerned with cities rather than states, as in his paper, and that we also include individuals who are foreign born. When we estimate the wage equations, the selection correction terms enter significantly, which suggests that there are selection effects. Our results with or without the Dahl procedure are very similar, which is to be expected since our instruments should induce movements in wages that are uncorrelated with the characteristics of the workforce. Nevertheless, all estimates presented below include the selection corrected wages. ${ }^{18}$

${ }^{15}$ Our data was extracted from IPUMS, see Ruggles, Sobek, Alexander, Fitch, Goeken, Hall, King, and Ronnander (2004)

${ }^{16}$ We take a flexible approach to specifying the first-stage regression. We include indicators for education (4 categories), a quadratic in experience, interactions of the experience and education variables, a gender dummy, black, hispanic and immigrant dummy variables, and the complete set of interactions of the gender, race and immigrant dummies with all the education and experience variables.

${ }^{17}$ Since the number of cities is large, adding the selection probability for each choice is not practical. Therefore, Dahl (2002) suggests an index sufficiency assumption that allows for the inclusion of a smaller number of selection terms, such as the first-best or observed choice and the retention probability. This is the approach that we follow.

${ }^{18}$ Details on the implementation of Dahl's procedure are contained in Appendix E. Results without the selection 
One of our main covariates of interest is the $\Delta R_{c t}$ variable which is a function of the national-industrial wage premia and the proportion of workers in each industry in a city. We estimate the wage premia in a regression at the national level in which we control for the same set of individual characteristics described for our first-stage wage regression and also include a full set of industry dummy variables. This regression is estimated separately for each Census year. The coefficients on the industry dummy variables are what we use as the industry premia in constructing our $R$ measures.

The dependent variable in our analysis is the log change in industry-city-level employment rates. We construct the industry-level employment rate by summing the number of individuals working in that particular industry divided by the city working-age population. Using employment to population ratios means that we include individuals who are classified as being out of the labor force as being relevant for labor market tightness. This is consistent with previous work on matching functions (Blanchard and Diamond, 1989) and on local labor market conditions (Bartik, 2006). Nevertheless, we have assessed the sensitivity of our results to this assumption and found it to be robust to an alternative definition of employment rates that restricts the population to include only those individuals that report themselves as being in the labor force. ${ }^{19}$ For most of our estimates, we use decadal differences within industry-city cells for each pair of decades in our data (1980-1970, 1990-1980, 2000-1990) plus the 20072000 difference, pooling these together into one large dataset and including period specific industry dummies. In all the estimation results we calculate standard errors allowing for clustering by city and year. ${ }^{20}$

\section{Results}

We begin the discussion of our results by presenting estimates of the first-stage, or reduced form, wage equation. These echo results presented BGS where the focus is precisely on the estimation of the impact of industrial composition shifts on wages, though the specifications are not identical because our focus, here, is on the reduced form. ${ }^{21}$

The columns of Table 1 contain estimates for potential first-stage wage equations. In columns 1 and 2, we regress wage changes on $I V 1_{c t}$ and $I V 2_{c t}$, respectively. This and all subsequent specifications include a full set of year-by-industry dummies $(4 \times 144)$, but we suppress the presentation of these coefficients for brevity. The key point from these columns is that both $I V 1_{c t}$ and $I V 2_{c t}$ are strong and highly significant determinants of $\Delta \ln w_{i c t}$. Re-

correction are very similar to those reported here, and are available upon request.

${ }^{19}$ We have also assessed the sensitivity of our results to using efficiency weighted counts of workers. In this case, we calculate employment rates as before, but weighing observations by the relative average wage of their demographic group throughout our time period. This has little impact on our results. Estimates using this specification are available upon request.

${ }^{20}$ We cluster at the city-year level because this is the level of variation in our data. Clustering only by city has little effect on the estimates of standard errors that we report.

${ }^{21}$ BGS focus on investigating and interpreting the impact of $\Delta R_{c t}$ on $\Delta \ln w_{i c t}$. They argue that their estimates imply that the impact of a change in industrial composition on the average wage in a city is approximately 3.5 times what is implied by a standard decomposition approach once spill-over effects from bargaining are taken into account. 
call from our earlier discussion that $I V 1_{c t}$ and $I V 2_{c t}$ correspond to quite different parts of the variation in $\Delta R_{c t}$ but the theory implies that they should have the same effect on bargaining power and, hence, on wages. The estimated coefficients on the two variables are very similar, and we cannot reject the restriction that they are equal at any conventional significance level. We view this as a strong piece of supportive evidence for the model. In the last column of table 1, we include both $I V 1$ and $I V 2$ to show that they are both individually helpful in predicting wages.

\subsection{Estimates of the Job Creation Curve: Basic Results}

In Table 2, we present estimates of our main equation of interest (16). As in table 1, all the reported regressions include a full set of year-by-industry dummies. Column (1) reports OLS results. Both the coefficients on the wage and the city-level employment rate are positive and highly significant. This is the opposite of what our theory predicts for consistent estimates of the coefficients in (16). However, the employment rate and wage equations derived from the model imply that OLS estimation of this equation should not provide consistent estimates. Moreover, the fact that productivity shocks, $\epsilon_{i c t}$, enter the wage and employment rate equation error terms suggests that the OLS regression coefficients are likely to be positive.

Columns (2-4) contain results from estimates of (16) using the $I V 1$ and $I V 2$ instruments developed in section (1.4). As we saw in Table 1, the instruments perform well in the firststage. F-statistics for wages are reported in the bottom rows of Table (2), supporting our claim that our instruments are good predictors of within-industry wage changes and we do not face weak instrument concerns.

The IV results indicate that labor costs are negatively associated with sector employment rates, as predicted by theory. The magnitude of the estimated coefficients on $\Delta \ln w_{\text {ict }}$ obtained from either $I V 1$ or $I V 2$ are nearly identical, and a standard over-id test fails to reject the null hypothesis of equality at any conventional significance level. ${ }^{22}$ As argued earlier, we view this result as being particularly important. From a theoretical point of view, bargaining implies that improvements in workers' outside employment opportunities should have the same impact on wages regardless of whether the improvements arise from growth in a high paying industry in a locality (the variation emphasized in $I V 1_{c t}$ ) or increases in industrial premia in existing industries (the variation emphasized in $I V 2_{c t}$ ). Given this, we also expect labor demand responses estimated from either source of variation to be the same since employers are only concerned about the bargained wage. From an empirical point of view, this result provides an important test of our identifying assumptions. Heuristically, since both instruments are valid under the same assumptions but rely on very different sources of variation, departures from these assumptions will be weighted differently by the two instruments, causing estimates to diverge. The fact that we do not observe this provides a stringent test of the validity of our instrumental variables approach and is a strong piece of evidence in favor of the search and bargaining model.

The other key prediction from the model is that an increase in labor market tightness

in a city (as represented by the city-level employment rate) should negatively affect within

\footnotetext{
${ }^{22}$ The actual test statistic value is 0.17 with a p-value of 0.68 .
} 
industry employment rates. Once we instrument, we do, in fact, find a strongly significant negative effect of $\Delta \ln \frac{E_{c t}}{L_{c t}}$ on $\Delta \ln \frac{E_{i c t}}{L_{c t}}$. This is a striking result since one would normally expect a positive relationship between these variables. As we discussed earlier, it is difficult to reconcile this result with a standard neoclassical model but it is a clear prediction of a search and bargaining model.

We are now in a position to interpret the results. Consider a wage increase in a particular industry, holding overall employment rates constant. If the industry in question is not so large as to have a significant impact on overall employment rates, the estimates using $I V 1$ and $I V 2$ as instruments in Table 2 imply a labor demand elasticity at the industry level of about -1 .

What about improvements of wages in a city more generally? Since all industries will adjust employment downward in response to a general wage increase, there will be feedback effects on overall employment rates. Allowing these equilibrium effects to play out implies a city-level labor demand elasticity of $\frac{\varphi_{2}}{1-\varphi_{3}}$ or of about -0.30 given our estimates. In other words, since $\varphi_{3}$ is predicted to be less than zero in a search and bargaining model, overall wage increases in a locality have a built in dampening effect on employment responses because they simultaneously increase the availability of workers. In our model, this leads to reduced search costs for firms (because vacancy contact rates are higher) or improved average entrepreneur quality (which can be thought of as a reduction in entry costs). Thus, our estimates suggest that city-level job creation curves are relatively wage inelastic; with an increase in wages of $10 \%$ impling a reduction in the city-level employment rate of about $3 \%$. Since we are particularly interested in the elasticity of job creation at the city level, in the following section we pursue a more direct route to evaluating it.

\subsection{City Wide Specification}

In the previous subsection, we addressed the reflection problem relating to city-wide employment rates via instrumental variables. In this subsection, we use the alternative approach of solving out for city employment rates. We view this approach as an additional check on our identification strategy. We begin by substitituting (20) into (16) to obtain a reduced form specification:

$$
\Delta \ln \frac{E_{i c t}}{L_{c t}}=\left(\varphi_{i t}+\varphi_{2} \cdot d_{i t}\right)+\varphi_{2} \cdot \beta_{2} \Delta R_{c t}+\left(\varphi_{2} \cdot \beta_{3}+\varphi_{3}\right) \cdot \Delta \ln \frac{E_{c t}}{L_{c t}}+\left(\varphi_{2} \Delta \xi_{i c t}+\zeta_{i c t}\right) .
$$

Aggregating over industries, we can rewrite (24) as:

$$
\Delta \ln \frac{E_{c t}}{L_{c t}}=\sum_{i} \eta_{i c t-1} \cdot \frac{\varsigma_{i t}}{1-\varsigma_{3}}+\frac{\varsigma_{2}}{1-\varsigma_{3}} \Delta R_{c t}+\sum_{i} \eta_{i c t-1} \frac{\varsigma_{i c t}}{1-\varsigma_{3}}
$$

where $\varsigma_{i t}=\varphi_{i t}+\varphi_{2} \cdot d_{i t}, \varsigma_{2}=\varphi_{2} \cdot \beta_{2}, \varsigma_{3}=\varphi_{2} \beta_{3}+\varphi_{3}$, and $\varsigma_{i c t}=\varphi_{2} \Delta \xi_{i c t}+\zeta_{i c t}{ }^{23}$ Noticing that $\varsigma_{i t}$ relates to national-level industry growth rates, it can be $\operatorname{shown}^{24}$ that $\sum_{i} \eta_{i c t} \cdot \varsigma_{i t}$ can be translated into a set of year dummies and the term $\sum_{i} \eta_{i c t-1} \cdot g_{i t}$, where $g_{i t}$ is the growth rate

${ }^{23}$ In performing this aggregation, we have made use of the approximation $\sum_{i} \eta_{i c t-1} \Delta \ln \frac{E_{i c t}}{L_{c t}} \approx \Delta \ln \frac{E_{c t}}{L_{c t}}$.

${ }^{24}$ To see this, rewrite (24) as

$$
\Delta \ln E_{i c t}=\varsigma_{i t}+\varsigma_{2} \Delta R_{c t}+\varsigma_{3} \cdot \Delta \ln E_{c t}+\left(1-\varsigma_{3}\right) \cdot \Delta \ln L_{c t}+\varsigma_{i c t} .
$$


of employment in industry $i$ at the national level, as before. Hence, we can write a specification that aggregates over industries as:

$$
\Delta \ln \frac{E_{c t}}{L_{c t}}=d_{t}+\frac{1}{1-\varsigma_{3}} \cdot \sum_{i} \eta_{i c t-1} \cdot g_{i t}+\frac{\varsigma_{2}}{1-\varsigma_{3}} \Delta R_{c t}+\sum_{i} \eta_{i c t-1} \frac{\varsigma_{i c t}}{1-\varsigma_{3}},
$$

where $d_{t}$ represents a set of year dummy variables and $\sum_{i} \eta_{i c t-1} \frac{\varsigma_{i c t}}{1-\varsigma_{3}}$ is the new error term. The variable $\sum_{i} \eta_{i c t-1} \cdot g_{i t}$ is city-level predicted employment growth and is the same variable we used to instrument $\Delta \ln \frac{E_{c t}}{L_{c t}}$ in the industry-city level equations. Under our maintained assumption, it is uncorrelated with the error term. Also notice that the model implies that its coefficient, $\frac{1}{1-\varsigma_{3}}$, should be positive: cities with a high initial concentration in industries that grow well at the national level have a greater increase in their city level employment ratio. $\Delta R_{c t}$ is our index for changes in industrial composition and its coefficient, $\frac{\varsigma_{2}}{1-\varsigma_{3}}$ is predicted to be negative. The specification given in (26) says that if demand conditions are the same in cities $\mathrm{A}$ and $\mathrm{B}$, in the sense of having the same predicted employment growth rates, the city with the greater increase in $R_{c t}$ will have less actual growth in employment rates. In terms of the model, this occurs because increases in $R_{c t}$ cause an increase in the bargained wage, thus lowering job creation.

We present estimates of the city-level equation given in (26) in columns (1)-(4) of Table 3. This table has a format similar to Table $2 .{ }^{25}$ Because of our concern about the relationship of $\Delta R_{c t}$ with the error term, we instrument for it using $I V 1$ and $I V 2$. The instrumental variables results, given in columns (2)-(4) are in close accord with theory: increases in workers' bargaining positions, as captured by $\Delta R_{c t}$, decrease city-level employment growth while predicted growth has positive impacts.

We can now substitute (26) into (24) to obtain an industry-city level equation that eliminates $\Delta \ln \frac{E_{c t}}{L_{c t}}$ and, with it, the reflection problem:

$$
\Delta \ln \frac{E_{i c t}}{L_{c t}}=\lambda_{i t}+\lambda_{2} \cdot \Delta R_{c t}+\lambda_{3} \cdot \sum_{i} \eta_{i c t-1} \cdot g_{i t}+e_{i c t},
$$

where $\lambda_{i t}$ are time-varying industry dummies, $\varepsilon_{i c t}$ is an error term. One can easily verify that the model implies that $\lambda_{2}$ and $\lambda_{3}$ should be negative.

Estimates of (27) are given in columns (5)-(8) of Table 4. As can be seen from the instrumental variables results in columns (6)-(8), the estimated $\lambda_{2}$ is indeed negative, as predicted, and similar whether we use $I V 1$ or $I V 2$. It is also interesting to observe the estimated coefficient on the predicted growth variable, $\lambda_{3}$. In the industry-city level specifications it is negative, significantly different from zero, and very stable in all specifications. In contrast, the

Taking the sum of this equation over cities using the weights $\omega_{c}=\frac{E_{c 0}}{\sum_{c} E_{c 0}}$, where 0 denotes the initial year, gives:

$$
\sum_{c} \omega_{c} \Delta \ln E_{i c t}=\varsigma_{i t}+\varsigma_{2} \sum_{c} \omega_{c} \Delta R_{c t}+\varsigma_{3} \cdot \sum_{c} \omega_{c} \Delta \ln E_{c t}+\left(1+\varsigma_{3}\right) \cdot \sum_{c} \omega_{c} \Delta \ln L_{c t}+\sum_{c} \omega_{c} \varsigma_{i c t} .
$$

This implies that $\varsigma_{i t}$ can be written as $\varsigma_{i t}=\sum_{c} \omega_{c} \Delta \ln E_{i c t}+d_{t}-\sum_{c} \omega_{c} \varsigma_{i c t}$, where $d_{t}$ is a year fixed effect. Now taking the sum over $i$ : $\sum_{i} \eta_{i c t} \varsigma_{i t}=\sum_{i} \eta_{i c t} \cdot g_{i t}+d_{t}-\sum_{i} \eta_{i c t} \sum_{c} \omega_{c} \varsigma_{i c t}$. Since $\varsigma_{i c t}=\varphi_{2} \Delta \xi_{i c t}+\zeta_{i c t}$ and by assumption, $\sum_{c} \Delta \xi_{i c t}=\sum_{c} \zeta_{i c t}=0$, this last term behaves approximately like white noise. The term $d_{t}$ varies only by year and can be captured in an empirical specification by year dummies.

${ }^{25}$ Although we do not present the coefficients here, all estimates of specification (26) include year fixed effects. 
coefficient on the same variable in the city-level specification given by (26), $\frac{1}{1-\varsigma_{3}}$, is predicted and estimated to be positive. This sign reversal is possible because of the different variation used in each case. Given the inclusion of time varying industry effects, the estimated effect of predicted job growth in (27) is obtained from relative growth in employment rates across cities within an industry. National-level growth in that industry is soaked up in the industry effects and plays no role in identifying the coefficient on the demand measure. In the aggregate specification, (26), however, the national-level growth rates are part of the relevant variation. The key point is that the switching of the sign of the coefficient on predicted employment growth when we switch the identifying variation in this way is a restriction implied by the theory. ${ }^{26}$ We view the fact that the data are supportive of this restriction as further evidence in favor of the model.

Just as we obtained equation (26) by aggregating over the reduced from specification (24), we can perform similar calculations to directly get a specification at the city level by aggregating over (16):

$$
\Delta \ln \frac{E_{c t}}{L_{c t}}=d_{t}+\frac{1}{1-\varphi_{3}} \cdot \sum_{i} \eta_{i c t-1} \cdot g_{c t}+\frac{\varphi_{2}}{1-\varphi_{3}} \cdot \sum_{i} \eta_{i c t-1}\left(\Delta w_{i c t}-\Delta w_{i t}\right)+\tilde{\zeta}_{c t},
$$

where $d_{t}$ represent year fixed effects and $\tilde{\zeta}_{c t}$ is an error term. ${ }^{27}$ The variable $\sum_{i} \eta_{i t-1} \cdot\left(\Delta \ln w_{i c t}-\Delta w_{i t}\right)$ represents the change in the average city wage relative to the national average.

Estimates of (28) are presented in Table 5. This table has a similar format to those that proceed it, and also contains a full set of year dummies. IV estimates of the coefficient $\frac{\varphi_{2}}{1-\varphi_{3}}$ in columns (2)-(4) range from about -0.27 to -0.31 , which can be interpreted as city-level elasticities of labor demand with respect to wages. Recall from Table 2, which examines the baseline industry-city level equation (16), we obtained estimates of $\varphi_{2}$ and $\varphi_{3}$ of about -1 and -2 , respectively. We argued that this implied city-level wage elasticities of $\frac{\varphi_{2}}{1-\varphi_{3}} \approx-0.3$, which is precisely what is obtained in our alternative, city-level approach.

\section{Robustness and Specification Tests}

In this section, we assess the sensitivity of our results to a variety of specification checks.

\subsection{Exploring the Effects of Labor Force Size on Employment Determination}

Table 6 contains results from our baseline specification (16) and our aggregated specification (28) where we include labor force growth as an additional control variable. Under the assumptions of the model (specifically, that the matching function exhibits constant returns to scale

\footnotetext{
${ }^{26}$ The negative effect of an increase in aggregate demand on job creation within an industry arises in the model because (1) it lowers the vacancy contact rate (through $\alpha_{2}$ in equation (13)), and (2) it increases the bargained wage (through $\beta_{3}$ in equation (20)). The coefficient $\lambda_{3}$ is equal to $\frac{\varphi_{2} \cdot \beta_{3}+\varphi_{3}}{1-\varphi_{2} \cdot \beta_{3}-\varphi_{3}}=\frac{\alpha_{2} \cdot \beta_{3}+\alpha_{3}}{\theta_{1}-\alpha_{2} \cdot \beta_{3}-\alpha_{3}}<0$. Increases in the bargained wage occur because lower contact rates for vacancies essentially shifts bargaining power in the workers' favor.

${ }^{27}$ In deriving equation (28), we have again made use of the approximation $\sum_{i} \eta_{i c t-1} \cdot \Delta \ln \frac{E_{i c t}}{L_{c t}} \approx \Delta \ln \frac{E_{c t}}{L_{c t}}$. The variable $\sum_{i} \eta_{i c t-1} \cdot g_{c t}$ in this specification can be justified along the same lines as footnote 24, except that we must now take into account changes in national-level industrial premia, resulting in the variable $\sum_{i} \eta_{i c t-1}\left(\Delta w_{i c t}-\Delta w_{i t}\right)$.
} 
and that the number of entrepreneurs is proportional to the labor force), changes in the size of the labor force should have no impact on employment rates once we control for local demand conditions and labor costs. The estimated coefficient on labor force growth in these equations serves as a check on these assumptions. The first column shows OLS estimates, while in columns (2)-(4) we instrument for changes in within-industry wage and city employment rates. In columns (1)-(4), we do not instrument the city's labor force variable. Interestingly, when we instrument the wages and employment rate when including the labor force growth variable the estimated coefficients on $\Delta \ln w_{i c t}$ and $\Delta \ln \frac{E_{c t}}{L_{c t}}$ change very little from the results presented in Table 2. It should be kept in mind that since we are examining decadal differences, these results should be interpreted as long-term consequences of increasing the size of a city's labor force.

Since the growth in labor force is not likely to be exogenous, finding that it does not enter significantly in columns (1)-(4) cannot be used to infer that it does not affect the employment rate, since its coefficient is likely biased. We attempt to address this possibility by constructing an instrument set for labor force growth that is based on long-term city climate variables. Since mobility is likely driven by local amenities, variation in local amenities would potentially provide a good set of instruments. However, most amenities (not related to employment and wages) are relatively constant over time, making them unhelpful as instruments in our difference specification. Nonetheless, measures of amenities can still be used as instruments in this case if the value of the amenity has changed over time. For example, if the value of living in a nice climate has increased over time then the level of the climate indicator variable can be used as an instrument variable for labor force growth. ${ }^{28}$ Building on this insight, we collected data from a number of sources to construct an instrument set consisting of average temperatures and precipitation for each city in our sample. Consistent with the idea that workers are increasingly drawn to cities by amenity factors, we find that indicators of mild climates are significant predictors of city labor force growth. ${ }^{29}$

The estimates in column (5) of Table 6 show the results using all of the instruments including the climate variables. The first stage F-statistic on labor force growth, reported in the second last row of the table, is 24.0, indicating that we predict labor force growth quite well. The estimated coefficient (standard error) on the labor force growth variable is $-0.12(0.072)$, which is larger than the non-instrument results but still not statistically significant. The estimated coefficients on $\Delta \ln w_{i c t}$ and $\Delta \ln \frac{E_{i c t}}{L_{c t}}$, are slightly lower, but still imply a city labor demand elasticity of $\frac{-.77}{1+1.28}=-0.34$, which is in line with our previous estimates. In column 6 , we report results from the city-level specification (28) with labor force growth included and using the climate instruments. This exercise provides support for the idea that a job creation curve - which represents a trade-off between wages and employment rates- is likely a better specification for examining the wages effect on employment than a more traditional labor

${ }^{28}$ This idea comes from Dahl (2002) who empirically tests a Roy (1951) model of self-selection of workers across states. He finds that while migration patterns of workers are partially motivated by comparative advantage, amenity differences across states also play a role in worker movements.

29 The validity of the climate instruments rests on the assumption that the relationship between city climate and city-industry job creation and cost advantages (the $\Omega \mathrm{s}$ and $\epsilon \mathrm{S}$ ) is constant over time. In this case, the relationship is entirely captured in time-invariant city-specific effects that are differenced out of the estimating equation. This assumption may not be valid if the evolution of these advantages are related to long-term climate conditions. 
demand specification where the dependent variable would be the level of employment.

\subsection{Exploring Worker Heterogeneity}

The model we developed in section 1 conceptually applies to workers of a single skill group. In section 1.5 we discussed how we address worker heterogeneity while at the same time focusing on the workforce as a whole. In this section, we assess this approach in two ways. First, we evaluate the sensitivity of our results to including variables designed to capture changes in the skill distribution of a city's labor force. As discussed earlier, in a version of the model with perfectly substitutable bundles of efficiency units of work, the skill distribution of the labor force can affect job creation. We argued that we expect this effect to be second order in size but we wish to assess that expectation. Second, in keeping with the conceptual idea that the model may apply best to workers of a single type, we estimate our basic specification separately for workers with high school education or less and those with some post secondary or more.

Table 7 presents results obtained by adding additional regressors to capture changes in the skill distribution of a city's workforce. The first variable we construct is the average efficiency units per person. ${ }^{30}$ Increases in this variable indicate that the workers in a city have become, on average, more productive and is designed to capture the effect that a firm opening a new vacancy has a higher probability of meeting a higher quality worker. We also construct an instrument designed to capture plausibly exogenous movements in this variable. To do this, we draw on literature that uses "enclaves" to predict immigration flows. In particular, we exploit the fact that immigrants from different sending countries have on average different educational attainment as well as other observable characteristics that influence a worker's efficiency weight. We construct this instrument as follows: we assume immigrants from sending country $h$ entering the country over a particular decade, denoted by $M_{h t}$, choose cities based on where previous waves of immigrants from the same sending country had settled. Denote the fraction of immigrants from sending country $h$ living in city $c$ at time $t$, as $\lambda_{h c t}$. The predicted number of immigrants that will move to city $c$ in year $t, \hat{M}_{c t}$, can be written as:

$$
\hat{M}_{c t}=\sum_{h} \lambda_{h c t-1} \cdot M_{h t}
$$

Similarly, we can construct the predicted number of workers in efficiency units that move to city $c$ in year $t$ as $\hat{M}_{c t}^{E U}=\sum_{h} \lambda_{h c t-1} \cdot M_{h t} \cdot \omega_{h t-1}$, where $\omega_{h t-1}$ is the efficiency weight per worker from sending country $h$ in the base year. To predict changes in the average efficiency units per worker, assuming no other changes in population, we construct the following instrument:

$$
I V_{c t}^{E U}=\left(\frac{\hat{M}_{c t}^{E U}}{\hat{M}_{c t}}-E U_{c t-1}\right) \cdot \frac{\hat{M}_{c t}}{\hat{M}_{c t}+L_{c t-1}},
$$

where $\frac{\hat{M}_{c t}^{E U}}{\hat{M}_{c t}}$ is the predicted average efficiency units per worker arriving in city $c$ in year $t .{ }^{31}$

\footnotetext{
${ }^{30}$ For additional details on how we calculate efficiency units, see Appendix B.

${ }^{31}$ The formulation of this instrument is similar to Doms and Lewis (2006), and in the same spirit as Card and DiNardo (2000) and Card (2001, 2009), among others.
} 
The results that include changes in efficiency units per worker as an additional control are presented in columns (1)-(4) of Table 7. In the first column, where all variables are treated as if exogenous, the change in efficiency units per worker does not enter significantly. IV results are given in columns (2)-(4), where we include $I V_{c t}^{E U}$ in the instrument set. In line with previous literature, the immigration enclave instrument predicts changes in a city's skill composition quite well. ${ }^{32}$ Nevertheless, in no specification is the skill variable significant, and, more importantly, it alters the magnitude of the estimated demand elasticities very little. To further probe sensitivity of our results to changes in city skill distribution, columns (5)-(8) add alternative measures of a city's skill. In columns (5) and (6), we include the change in the fraction of college graduates as an additional control. When treated exogenously, as in column (5), it enters significantly but does not change the main conclusions regarding demand elasticities. In column (6), we instrument the change in the proportion of college graduates with an enclave instrument similar to (29). ${ }^{33}$ This results in imprecise estimates that are not significantly different from zero despite a strong first-stage. In the remaining columns, (7) and (8), we include the change in the proportion of workers with education greater than high school. Again, inclusion of this variable does not alter the main conclusions of the paper thus far. We conclude that changes in a city's skill distribution have, at best, only a second order effect on job creation and do not appreciably affect the estimated magnitude of our key parameters.

In Table 8 we estimate our basic specification separately by education group. The education groups we consider are those with high school education or less and those with some post secondary or more. ${ }^{34}$ When we perform this exercise, we are assuming that there are two completely segregated markets defined by education. ${ }^{35}$ The dependent variable in Table 8 is the change in log city-industry employment rates for a particular education group. Similarly, wages and their instruments are constructed separately by education group. ${ }^{36}$ However, we maintain the use of aggregate, city-wide employment rates (over all education groups) to capture the effects of limited entrepreneurial talent (which should operate at the city level) and vacancy contact rates. ${ }^{37}$ Columns (1)-(4) pertain to the low-education group and columns (5)-(8) to the high-education group. The results for the low education group are very similar to those for the full sample. The results for the (smaller) post-secondary group are more erratic

\footnotetext{
${ }^{32}$ The first-stage t-ratio on $I V_{c t}^{E U}$ in the change in efficiency units per worker equation is over 8.0 in all specifications.

${ }^{33}$ In this case, the instrument is constructed in exactly the same way as Doms and Lewis (2006).

${ }^{34} \mathrm{We}$ have assessed the sensitivity of our results to finer breakdowns in education which typically resulted in very imprecise estimates. Finer skill definitions dramatically reduces the number of city-industry cells to work with, and, thus, produces sample size problems.

${ }^{35}$ Empirical evidence suggests that workers within our education classes are perfect substitutes, but that there is imperfect substitution of workers between the high- and low-education groups (Card, 2009). This latter type of substitution is ruled out in this framework.

${ }^{36}$ For example, $I V 1$ and $I V 2$ are constructed using city-industry shares and national wage premia that are estimated off of education specific samples.

${ }^{37}$ While it may be argued that vacancy contact rates for a particular education group would vary with education specific employment rates, using education specific employment rates made very little difference in practice. In addition, to the extent that one believes vacancy contact rates play little role in job creation compared to limited entrepreneurial ability, the aggregate employment rate specification would be preferred.
} 
but tend to imply a similar sized wage elasticity.

\subsection{Further Model Implications}

The multi-city, multi-sector search and bargaining model that we present implies that shifts in industrial composition toward or away from higher paying industries affect the bargained wage in all sectors of the local economy. This occurs because these shifts influence the outside options of workers, and we use this implication to obtain estimates of the elasticity of the job creation curve with respect to wages. As noted in our discussion of an extension of the model that incorporates worker mobility in section 1.6, these same shifts should be associated with worker mobility and changes in local housing prices. That is, conditional on the tightness of the labor market, a pure compositional shift toward higher paying industries will increase the average city wage and, thus, be associated with in-migration and higher housing costs. This is laid out more formally in Appendix D.

In this subsection, we briefly explore whether these predictions are born out in the data. Table 9 investigates whether changes in the within-industry average city wage and city-level employment rates are correlated with in-migration and housing prices, proxied by the rental rate of a two or three bedroom apartment. ${ }^{38}$ The table has a similar lay-out to previous ones: it contains regression coefficients estimated on our city-level data and all specifications contain year fixed-effects which are suppressed from the table. In the first four columns, the dependent variable is the log change of the size of a city's labor force. The first column is estimated via OLS, while the remaining three columns instrument for city wage using either $I V 1$ or $I V 2$ and using the Blanchard-Katz instrument used earlier for the employment rate. When we use our instruments, we find that both wages and employment rates enter significantly and indicate a positive association with in-migration as the mobility-extended model predicts. In the final four columns of the table, the dependent variable is the log change in the rent of a two or three bedroom apartment. Again, the estimated coefficients on city wages and employment rates are supportive of our interpretation of the data. That is, the forces in our model that drive wages also drive worker mobility flows, with housing prices being an equilibrating mechanism.

\section{Conclusion}

In this paper, we extend and estimate an empirically tractable version of a search and bargaining model. Our goal is to highlight the implications of such a model for labor demand and to provide estimates of the responsiveness of employment outcomes to changes in average wages. In a search and bargaining model, labor demand is determined by points along the job creation curve, which is implicitly defined by a zero marginal profit condition for the creation of a vacancy. According to this condition, when wages rise the tightness of the labor market must fall in order to maintain the value of creating jobs. Therefore, the job creation curve defines a relationship between wages and employment rates rather than employment levels, as in more standard set-ups. We argue that this seemingly small difference has substantial

\footnotetext{
${ }^{38}$ Appendix B contains details on the construction of this variable.
} 
implications. Chief among these is that shifts in labor supply and labor costs can produce very different labor market outcomes; that is, supply and wage shocks do not imply movements along the same demand curve in a search and bargaining model. This insight has the potential to explain some of the differences in labor demand elasticities that are presented in the literature.

In order to empirically evaluate the relevance of the search and bargaining framework, we extend an otherwise standard Pissarides (2000) model in several directions. First, our model includes multiple local labor markets linked through trade and labor mobility. There is substantial variation in employment levels and rates across cities, allowing for the identification of city-level job creation curves. Second, we extend the model to include multiple sectors, which is crucial for our identification strategy. Using insight developed in BGS, we use predicted industrial composition shifts to identify movements in average city wages induced by shifts in the outside options of workers. In a search and bargaining model, improvements in the outside employment opportunities of workers increases the bargained wage across all sectors within a locality. Finally, we extend the standard model to include heterogeneous talent across the population in terms of abilities to create jobs in different industries. With this extension, the job creation curve may be less than perfectly elastic because of both search costs and the limited availability job creators.

A key feature of this model is that it implies tight testable implications in the form of overidentifying restriction. We use U.S. Census data from 1970-2007 to investigate whether citylevel labor market outcomes conform to these restrictions. Working mainly at the industrycity level, our approach relies on comparing industry level changes in employment rates between cities with different changes in within-industry wages. We look at effects over periods of 10 years and, therefore, our estimates should be interpreted as representing long-run labor market outcomes. Importantly, we find that the model's main over-identifying restriction is easily passed in the data. While this observation does not necessarily prove that the theory is correct, we nevertheless believe that this provides compelling evidence in favor of the model. Based on this, we view estimates derived from this model as a reliable basis for assessing the impact of wage changes on employment outcomes.

The model implies two types of labor demand elasticities. The first corresponds to the effect of an increase in the cost of labor on a particular sector's employment rate while holding the overall tightness of the labor market in the city constant. Our estimate of that, partial equilibrium elasticity is close to -1 . We also examine how the local labor market as a whole reacts to a general increase in wages, allowing for interaction across sectors through the availability of workers and job creators. For this aggregate elasticity we obtain an estimate of approximately -0.3 . We view the aggregate elasticity as the relevant concept for most policy discussions and see our estimate as indicating a reasonable but relatively inelastic relationship. For example, our estimates suggest that a $15 \%$ increase in wage costs will be associated with an increase in unemployment of $5 \%$ (which in many cases would corrspond to doubling the unemeployment rate). Our model suggests that the somewhat low elasticity partly reflects a weak propensity for individuals to become more enterpreneurial and create more jobs as labor costs are reduced. This could arise either because the supply of new entrepreneurs is quite inelastic or because the creation of more jobs by existing entrepreneurs is limited by span of control 
problems. We hope to explore such mechanisms more in depth in future research.

Finally, the model provides a simple way to reconcile different estimates of the elasticity of labor demand obtained from policy shifts such as minimum wage or payroll tax changes versus from supply shifts. Within a search and bargaining model, the policy shifts correspond to increases in labor costs (a shift up in the wage bargaining curve) and, thus, can identify the slope of the job creation curve. In this sense, it is encouraging that our small estimated elasticity fits with the main body of estimated effects from these policies. Our estimates, though, stem from very different data variation and correspond to general wage increases that are relevant for the whole workforce. On the other hand, an increase in the size of the labor force, in contrast to a standard supply and demand model, does not trace out the equivalent of the labor demand curve in a search and bargaining model. Instead, it potentially affects labor market tightness, causing adjustments on both sides of the market. At this point, our finding that our results fit with a constant returns to scale specification of the matching function and the stock of entrepreneurial talent is important. Given this, an increase in labor force size (perhaps due to immigration) will not change the equilibrium employment rate or wage. Thus, employment will increase (in order to restore the equilibrium employment rate) but wages will not change and in employment - wage space this could be interpreted as reflecting a very elastic labor demand curve. Instead, our framework provides an explanation to this relation that does not imply that increases in wage costs will be associated with drastic reductions in employment.

\section{A Consistency}

We are interested in the conditions under which our instruments can provide consistent estimates. Apart from the instruments being correlated with $\Delta R_{i c}$ and $\Delta w_{i c}$, the condition we require for a given instrument, $Z_{c}$, is

$$
\lim _{C, I \rightarrow \infty} \frac{1}{I} \frac{1}{C} \sum_{i} \sum_{c} Z_{c} \Delta \zeta_{i c}=0 .
$$

We will handle the limiting arguments sequentially, allowing $C \rightarrow \infty$ first. ${ }^{39}$ Recall that $I V 1$ is given by:

$$
Z_{c}=\sum_{j} \eta_{j c}\left(g_{j}^{*}-1\right)\left(w_{j}-w_{1}\right)
$$

where $g_{j}^{*}=\frac{1+g_{j}}{\sum_{k} \eta_{k c}\left(1+g_{k}\right)}$ and $g_{j}$ is the growth rate in employment in industry $j$ at the national level. Given this, (A-1) becomes:

$$
\lim _{C \rightarrow \infty} \frac{1}{C} \sum_{j}\left(w_{j}-w_{1}\right) \sum_{c} \eta_{j c}\left(g_{j}^{*}-1\right) \sum_{i} \Delta \zeta_{i c} .
$$

We can derive an equation for shares as:

$$
\eta_{i c}=\frac{\tilde{\Omega}_{i c} \cdot F\left(V_{i c}^{v}\right)}{\sum_{i} \tilde{\Omega}_{i c} \cdot F\left(V_{i c}^{v}\right)}
$$

\footnotetext{
${ }^{39}$ Throughout this appendix we omit the $t$ subscript for simplicity.
} 
Taking linear approximation, again, around the point where $\Omega_{i c}=\epsilon_{i c}=0$ yields the following expression: ${ }^{40}$

$$
\eta_{i c} \approx \frac{1}{I}+\pi_{1}\left(\epsilon_{i c}-\frac{1}{I} \sum_{i} \epsilon_{i c}\right)+\pi_{2}\left(\Omega_{i c}-\frac{1}{I} \sum_{i} \Omega_{i c}\right)
$$

The $\pi \mathrm{s}$ are positive coefficients obtained from linear approximation. We can decompose the $\epsilon \mathbf{S}$ and $\Omega$ s into absolute and comparative advantages, $\epsilon_{i c}=\hat{\epsilon}_{c}+v_{i c}^{\epsilon}$ and $\Omega_{i c}=\hat{\Omega}_{c}+v_{i c}^{\Omega}$, which gives:

$$
\eta_{i c}=\frac{1}{I}+\pi_{1} \cdot v_{i c}^{\epsilon}+\pi_{2} \cdot v_{i c}^{\Omega}
$$

Similarly, substituting $\epsilon_{i c}=\hat{\epsilon}_{c}+v_{i c}^{\epsilon}$ and $\Omega_{i c}=\hat{\Omega}_{c}+v_{i c}^{\Omega}$ into the last term of (A-3), gives:

$$
\sum_{i} \Delta \zeta_{i c}=\lambda_{1} \cdot I \cdot \Delta \hat{\epsilon}_{c}+\lambda_{2} \cdot I \cdot \Delta \hat{\Omega}_{c}
$$

which depends only on the increments of the absolute advantage components. From equation (A-6), the city-industry shares depend only on the relative advantage components. Thus, (A3) equals zero provided that $E\left(\Delta \hat{\epsilon}_{c}\right)=E\left(\Delta \hat{\Omega}_{c}\right)=0$, and that $\Delta \hat{\epsilon}_{c}$ and $\Delta \hat{\Omega}_{c}$ are independent of past values of the relative advantage components, $v_{i c}^{\epsilon}$ and $v_{c}^{\Omega}$. In other words, general improvements in a city must be unrelated to past industry relative advantages.

Similarly, the relevant condition when using $I V 2$ is given by

$$
\lim _{C \rightarrow \infty} \frac{1}{C} \sum_{j} \Delta\left(w_{j}-w_{1}\right) \sum_{c} \eta_{j c} \sum_{i} \Delta \zeta_{i c}
$$

and the same conditions ( $\Delta \hat{\epsilon}_{c}$ to be independent of past values of $v_{i c}^{\epsilon}$ and of $v_{i c}^{\Omega}$ ) ensure that this condition equals zero.

An important point follows from this discussion. If the key identifying assumption underlying the IVs is not true (i.e., changes in absolute advantage are not independent of past comparative advantage) then the two IV's weight the problematic correlation (between $\Delta \hat{\epsilon}_{c}$ and $v_{i c}^{\epsilon}$ ) differently (in particular, $I V 1$ weights using the weights $\left(w_{j}-w_{1}\right)$, while $I V 2$ uses the weights $\left.\Delta\left(w_{j}-w_{1}\right)\right)$ and estimates based on the different IVs should differ.

\section{B Data}

The Census data was obtained with extractions done using the IPUMS system (see Ruggles, Sobek, Alexander, Fitch, Goeken, Hall, King, and Ronnander (2004). The files were the 1980 5\% State (A Sample), 1990 State, 2000 5\% Census PUMS, and the 2007 American Community Survey. For 1970, Forms 1 and 2 were used for the Metro sample. The initial extraction includes all individuals aged 20 - 65 not living in group quarters. All calculations are made using the sample weights provided. For the 1970 data, we adjust the weights for the fact that we combine two samples. We focus on the log of weekly wages, calculated by dividing wage and salary income by annual weeks worked. We impute incomes for top coded values by

\footnotetext{
${ }^{40}$ Recall that if $\Omega_{i c}=\epsilon_{i c}=0$ then the industry shares are equal across cities. We further assume, for simplicity, that the shares are equal to $\frac{1}{I}$ at this point.
} 
multiplying the top code value in each year by 1.5. Since top codes vary by State in 1990 and 2000, we impose common top-code values of 140, 000 in 1990 and 175, 000 in 2000.

A consistent measure of education is not available for these Census years. We use indicators based on the IPUMS recoded variable EDUCREC that computes comparable categories from the 1980 Census data on years of school completed and later Census years that report categorical schooling only. To calculate potential experience (age minus years of education minus six), we assign group mean years of education from Table 5 in Park 1994 to the categorical education values reported in the 1990 and 2000 Censuses.

Census definitions of metropolitan areas are not comparable over time since, in general, the geographic areas covered by them increase over time and their definitions are updated to reflect this expansion. The definition of cities we use attempts to maximize geographic comparability over time and roughly correspond to 1990 definitions of MSAs provided by the U.S. Office of Management and Budget. ${ }^{41}$ To create geographically consistent MSAs, we follow a procedure based largely on Deaton and Lubotsky (2001) which uses the geographical equivalency files for each year to assign individuals to MSAs or PMSAs based on FIPs state and PUMA codes (in the case of 1990 and 2000) and county group codes (for 1970 and 1980). Each MSA label we use is essentially defined by the PUMAs it spans in 1990. Once we have this information, the equivalency files dictate what counties to include in each city for the other years. Since the 1970 county group definitions are much courser than those in later years, the number of consistent cities we can create is dictated by the 1970 data. This process results in our having 152 MSAs that are consistent across all our sample years. Code for this exercise was generously provided by Ethan G. Lewis. Our definitions differ slightly from those in Deaton and Lubotsky (2001) in order to improve the 1970-1980-1990-2000 match.

We use an industry coding that is consistent across Censuses and is based on the IPUMS recoded variable IND1950, which recodes census industry codes to the 1950 definitions. This generates 144 consistent industries. ${ }^{42}$ We have also replicated our results using data only for the period 1980 to 2000, where we can use 1980 industry definitions to generate a larger number of consistent industry categories. ${ }^{43}$ We are also able to define more (231) consistent cities for that period.

We create a variable to proxy for the cost of housing in a city by using a measure of the rental rate of a two or three bedroom apartment in that city. To construct this variable, we use the Census variable for 'contract rent' and restrict it to the reported rent for two or three bedroom apartments in each of our MSAs. This is a similar procedure to that used recently by Moretti (2008). See that paper for a discussion on the appropriateness of this measure for local housing costs.

Efficiency units are constructed by dividing the data, in each year, into demographic cells defined by potential experience (5 categories), education (4 categories), gender, and immi-

\footnotetext{
${ }^{41}$ See http://www.census.gov/population/estimates/pastmetro.html for details.

${ }^{42}$ See http://usa.ipums.org/usa-action/variableDescription.do?mnemonic=IND1950 for details.

43 The program used to convert 1990 codes to 1980 comparable codes is available at http://www.trinity.edu/bhirsch/unionstats . That site is maintained by Barry Hirsch, Trinity University and David Macpherson, Florida State University. Code to convert 2000 industry codes into 1990 codes was provided by Chris Wheeler and can be found at http://research.stlouisfed.org/publications/review/past/2006. See also a complete table of 2000-1990 industry crosswalks at http://www.census.gov/hhes/www/ioindex/indcswk2k.pdf
} 
grant status. We then calculate the average weekly wage and share of employment for each cell by year. We create a set of fixed-weights by averaging the employment shares for each demographic group across years, and construct an index of wages by year by taking the fixedweighted average of wages in each year. Our measure of efficiency weights uses the average value of index for each cell over the number of years of our data set. When calculating efficiency units of workers, we use the efficiency weight multiplied by the sampling weight for each worker.

\section{B.1 Enclave Instrument}

The construction of the enclave instrument is similar to that of Doms and Lewis (2006) and uses their origin country groupings. The country of origin groups are (1) Mexico, (2) Central America, (3) South America, (4) Central Europe and Russia, (4) Caribbean, (5) China, (6) South East Asia, (7) India, (8) Canada, U.K., and Australia, (10) Africa, (11) Korea and Japan, (12) Pacific Islands, (13) Israel and NW Europe, (14) Middle East, (15) Central Asia, (16) Cuba, and (17) Souther Europe and can be identified from the IPUMS variable bpl ' Birthplace [general version]' ' . To identify the inflows of immigrants, we use the IPUMS variable yrimmig "Year of immigration"'.

\section{B.2 Climate Instrument}

The city level climate variables were extracted from "Sperling's Best Places to Live"

(http://www.bestplaces.net/docs/DataSource.aspx). Their data is compiled from the National Oceanic and Atmospheric Administration. The variables we use in this paper are the average daily high temperatures for July and January in degrees Fahrenheit. Alternative variables available from the same source are annual rainfall in inches and a comfort index. The comfort index is a variable created by "Sperling's Best Places to Live" that uses afternoon temperature in the summer and local humidity to create an index in which higher values reflect greater "comfort". We have also compiled climate data from an alternative source to use as a robustness check. These data come from "CityRating.com's" historical weather data, and include variables on average annual temperature, number of extreme temperature days per year, humidity, and annual precipitation. Data from this source could only be collected for 106 cities, and, therefore, not included in this analysis.

\section{Worker Heterogeneity}

Consider a simple search and bargaining model in which there are two types of workers: high- and low-skill. Let $\theta$ denote the fraction of high-skill workers and $\eta>1$ denote relative productivity of high versus low skill workers. 
The Bellman equations for firms can be written as: ${ }^{44}$

$$
\begin{array}{r}
r V=-\gamma+\phi \cdot\left(\theta \cdot J_{H}+(1-\theta) \cdot J_{L}-V\right) \\
r J_{i}=\eta_{i} \cdot p-w_{i}+s \cdot\left(V-J_{i}\right)
\end{array}
$$

Combining (C-9) and (C-10), gives the value of a vacancy:

$$
r V=\frac{-(r+s) \cdot \gamma+\phi\left(\theta \cdot\left(\eta \cdot p-w_{H}\right)+(1-\theta) \cdot\left(p-w_{L}\right)\right)}{r+s+\phi} .
$$

Workers of each skill type of the following Bellman equations:

$$
\begin{gathered}
r U_{i}=b+\varphi \cdot\left(E_{i}-U_{i}\right) \\
r E_{i}=w_{i}+s\left(U_{i}-E_{i}\right),
\end{gathered}
$$

for type $i \in\{$ High, Low $\}$. Wages are set according to the rule $(1-\beta)\left(E_{i}-U_{i}\right)=\beta\left(J_{i}-V\right)$. This gives

$$
w_{i}=(1-\beta) \cdot r U_{i}+\beta \cdot\left(\eta_{i} p-r V\right)
$$

The Bellman equations for workers gives $r U_{i}$ as

$$
r U_{i}=\frac{b \cdot(r+s)+\varphi\left(w_{i}\right)}{r+s+\varphi} .
$$

Hence, wages can be written as:

$$
w_{i}=\beta \Psi\left(\eta_{i} \cdot p-r V\right)+\frac{(1-\beta) \cdot \Psi \cdot b(r+s)}{r+s+\varphi}
$$

for each type where $\Psi=\frac{r+s+\varphi}{r+s+\beta \varphi}$. Then the wage differential between high- and low-skill workers is:

$$
w_{H}-w_{L}=\beta \Psi p \cdot(\eta-1)>0 .
$$

We can also calculate the difference in the flow profits for a firm meeting a high- versus lowskill worker:

$$
\left(\eta \cdot p-w_{H}\right)-\left(p-w_{L}\right)=p \cdot(\eta-1) \cdot(1-\beta \Psi)>0
$$

Notice that we can write the high-skill wage in terms of the low-skill wage, which rationalizes the use of regression adjusted wages. Also, we can rearrange the job creation equation so that it depends on low-skill wage, plus $\theta$ times the difference in flow of profits. This reduces the value of a vacancy to a function of three variables $r V=G\left(\theta, \frac{E}{L}, w_{L} ; \beta, \eta, r, s\right)$ where $\phi=\phi\left(\frac{E}{L}\right)$ and $\varphi=\varphi\left(\frac{E}{L}\right)$ are a function of the employment rate.

Setting $\gamma=0$, we can write

$$
r V=\frac{\phi}{r+s+\phi} \cdot\left(\theta \cdot p \cdot(\eta-1) \cdot(1-\beta \Psi)+p-w_{L}\right) .
$$

\footnotetext{
${ }^{44}$ Here, we assume that firms meeting either high- or low-skill workers will form matches. This can be seen as a restriction that $\eta$ cannot be too large.
} 
The term interacting with the skill variable, $\theta$, in equation $(\mathrm{C}-19)$ will be proportional to $(1-\beta \Psi)$, which is equal to:

$$
1-\beta \Psi=\frac{(1-\beta)(r+s)}{r+s+\beta \psi}
$$

If $r+s$ is small relative to $\psi$ (Blanchard, 1998), this term will also be small. Hence, we assume these skill effects only secondary and we can focus on $r V=\tilde{G}\left(\frac{E}{L}, w_{L} ; \beta, \eta, r, s\right)$. This justifies using efficiency wages while not making any adjustments for $\frac{E}{L}$ in the baseline empirical work. We assess the sensitivity of this assumption in a robustness section by including measures of city skill, skill breakdowns, and efficiency units. None of our results seem to be sensitive to any of these alternative specifications.

\section{Worker Mobility}

The purpose of this section is to extend our search and bargaining model to include worker mobility and to demonstrate that this extension does not change the main implications of our model. We consider two extensions of the model. In the first case, suppose unemployed workers have the option of occasionally switching cities. When this situation arises, with probability $\mu_{1}$, workers choose to move to the city that maximizes their expected utility, $\max _{c^{\prime}} U_{c^{\prime}}^{u}$. To incorporate this extension, we can write workers' unemployment Bellman equation as:

$$
\rho U_{c}^{u}=b+\tau_{c}+\left(1-\mu_{1}\right) \psi_{c} \cdot\left(\sum_{j} \eta_{j c} U_{j c}^{e}-U_{c}^{u}\right)+\mu_{1} \cdot\left(\max _{c^{\prime}} U_{c^{\prime}}^{u}-U_{c}^{u}\right),
$$

where we have assumed that $\mu=1$ to simplify exposition. ${ }^{45}$ The outside options of workers are now changed and wage negotiation will take this into account. Importantly, the form of this change does not alter any of our results because $\max _{c^{\prime}} U_{c^{\prime}}^{u}$ does not depend on workers' initial location and, therefore, is captured in our empirical specifications by year-by-industry dummy variables. It should be noted that in this case, however, the parameters we estimate will have a slightly different interpretation because they will depend on $\mu_{1}$ (the ease of switching cities).

In the second extension, we include housing prices and local amenities, as in the case of the Roback (1982) model. We continue to allow workers to search across cities and choose the city that maximizes expected utility, as above. When doing so, workers take into account local housing costs and amenities. To incorporate this extension, assume that workers care about wages, the price of housing in a city, $p_{c t}^{h}$, and about a local amenity, $\Psi_{c}$. In this case, a worker's (indirect) flow utility when employed in industry $i$ in city $c$ could be expressed as, $w_{i c}-\vartheta p_{c t}^{h}+\Psi_{c}$. Accordingly, his or her flow utility when unemployed will be given by $b+\tau_{c}-\vartheta p_{c t}^{h}+\Psi_{c}$. The first thing to notice about this extension is that housing prices do not directly impact wage negotiation because housing costs are incurred in both the employed and unemployed state. In order for expected utilities to equalize across cities, housing prices must adjust. To capture this, we summarize the functioning of the housing market by assuming that housing prices

\footnotetext{
${ }^{45}$ This is without loss and has the implication that unemployed flows depend only on city rather than industrycity.
} 
can be expressed as a positive function of the population of a city and of amenities, given by:

$$
p_{c t}^{h}=d_{0}+d_{1} \cdot L_{c t}+d_{2} \cdot \tau_{c}
$$

It is straight forward to derive an expression for housing prices, $p_{c t}^{h}$, that depends on local expected wages (and hence, on $R_{c t}$ ), amenities, and employment rates or labor market tightness. Housing prices will adjust such that a city with a favorable composition of jobs (due to the $\Omega \mathrm{s}$ and $\epsilon \mathrm{s}$ ) and higher amenities have benefits that are captured by local landowners. Wage differences across cities will not be equalized because in-migration will drive of local housing costs causing the movement of workers between cities to stop before wage equalization occurs. We conclude this section by noting that the forces emphasized in our model have testable implications for labor mobility and housing prices, but do not alter the main conclusions of our baseline model.

Finally, since in equilibrium workers will equalize expected utility across locations the term $\max _{c^{\prime}} U_{c^{\prime}}^{u}-U_{c}^{u}$ in equation D-21 will equal zero. Therefore, the equilibrium equations derived in the model section of this paper are not affected by this extension of worker mobility.

\section{E Selection Correction}

The approach we use to address the issue of selection on unobservables of workers across cities follows Dahl (2002). Dahl argues that, under a sufficiency assumption, the error mean term in the wage equation for individual $i$ can be expressed as a flexible function of the probability that a person born in $i$ 's state of birth actually chooses to live in city $c$ in each Census year. ${ }^{46}$ Dahl's approach is a two-step procedure that first requires estimates of the probability that $i$ made the observed choice and then adds functions of these estimates into the wage equation to proxy for the error mean term. Dahl also presents a flexible method of estimating the migration probabilities that groups individuals based on observable characteristics and uses mean migration flows as the probability estimates. We closely follow Dahl's procedure aside from several small changes to account for the fact that we use cities rather than states and to account for the location of foreign born workers.

Dahl's approach first groups observations based on whether they are "stayers" or "movers". Dahl defines stayers as individuals that reside in their state of birth in the Census year. Since we use cities instead of states, we define stayers as those individuals that reside in a city that is at least partially located in individual's state of birth in a given Census year. Movers are defined as individuals that reside in a city that is not located in that individual's state of birth in a given Census year. We also retain foreign born workers, whereas Dahl drops them. For these workers, we essentially treat them as "movers" and use their country of origin as their "state of birth" ${ }^{47}$ Within the groups defined as stayers, movers, and immigrants, we additionally divide observations based on gender, education (4 groups), age (5 groups), black, and hispanic indicators. Movers are further divided by state of birth. For stayers, we further

${ }^{46}$ This sufficiency assumption essentially says that knowing the probability of an individual's observed or "firstbest" choice is all that is relevant for determining the selection effect, and that the probabilities of choices that were not made do not matter in the determination of ones wage in the city where they actually locate.

${ }^{47}$ We use the same country of origin groups as for the enclave instrument. 
divide the cells based on family characteristics. ${ }^{48}$ Immigrants are further divided into cells based on country of origin as described above.

As in Dahl (2002), we estimate the relevant migration probabilities using the proportion of people within cells, defined above, who made the same move or stayed in their birth state. For each group, we calculate the probability that an individual made the observed choice and for movers, we follow Dahl in also calculating the retention probability (i.e. the probability that individual $i$ was born in a given state, and remained in a city situated at least partly in that state in general). For movers, the estimated probabilities that individuals are observed in city $c$ in year $t$ differ based on individuals' state of birth (and other observable characteristics). Thus, identification of the error mean term comes from the assumption that the state of birth does not affect the determination of individual wages, apart from through the selection term. For stayers, identification comes from differences in the probability of remaining in a city in ones birth state for individuals with different family circumstances. For immigrants, we assign the probability that an individual was observed in city $c$ in a given Census year using the probabilities from immigrants with the same observable characteristics in the preceding Census year. ${ }^{49}$ This follows the type of ethnic enclave assumption used in several recent papers on immigration, essentially using variation based on the observation that immigrants from a particular region tend to migrate to cities where there are already communities of people with their background.

Having estimated the observed choice or "first-best" choice of stayers, movers, and immigrants and the retention probability for movers, we can then proceed to the second step in adjusting for selection bias. To do this, we add functions of these estimated probabilities into the first stage individual-level regressions used to calculate regression adjusted average cityindustry wages. For movers, we add a quadratic of the probability that an observationally similar individual was born in a given state and was observed in a given city and a quadratic of the probability that an observationally similar individual stayed in their birth state. For stayers, we add a quadratic of the probability that an individual remained in their state of birth. For immigrants, we add a quadratic of the probability that an similar individual was observed in a given city in the preceding Census year. Dahl allows the coefficients on these functions to differ by state, whereas we assume that they are the same across all cities.

\section{References}

ACEmoglu, D. (1999): "Changes in Unemployment and Wage Inequality: An Alternative Theory and Some Evidence," American Economic Review, 89(5), 1259-1278.

— (2001): “Good Jobs versus Bad Jobs,” Journal of Labor Economics, pp. 1-22.

BARTElsman, E. J., AND M. DOMS (2000): "Understanding productivity: lessons from longitudinal microdata," Discussion paper.

\footnotetext{
${ }^{48}$ Specifically, we use single, married without children, and married with at least one child under the age of 5.

${ }^{49}$ For cities in the 1980 Census not observed in the 1970 Census, we use the 1980 probabilities.
} 
BARTIK, T. (1993): "Who Benefits from Local Job Growth: Migrants or the Original Residents?," Regional Studies, 27(4), 297-311.

BARTIK, T. J. (2006): "How Do the Effects of Local Growth on Employment Rates Vary With Initial Labor Market Conditions," Staff Working Papers 09-148, W.E. Upjohn Institute for Employment Research.

Beaudry, P., D. Green, AND B. SAND (2009): "Does Industrial Composition Matter? An empirical evaluation based on Search and Bargaining Theory," Working paper, University of British Columbia.

Blanchard, O. J., AND P. Diamond (1989): “The Beveridge Curve," Brookings Papers on Economic Activity, 20(1989-1), 1-76.

Blanchard, O. J., AND L. F. KATZ (1992): "Regional Evolutions," Brookings Papers and Economic Activity, (1), 1-75.

BlAU, F. D., AND L. M. KAHN (1999): "Institutions and laws in the labor market," in Handbook of Labor Economics, ed. by O. Ashenfelter, and D. Card, vol. 3 of Handbook of Labor Economics, chap. 25, pp. 1399-1461. Elsevier.

Boustan, L. P., P. V. Fishback, And S. E. Kantor (2007): “The Effect of Internal Migration on Local Labor Markets: American Cities During the Great Depression," NBER Working Papers 13276, National Bureau of Economic Research, Inc.

CARD, D. (1990): “The impact of the Mariel boatlift on the Miami labor market," Industrial and Labor Relations Review, 43(2), 245-257.

(2001): "Immigrant Inflows, Native Outflows, and the Local Labor Market Impacts of Higher Immigration,” Journal of Labor Economics, 19(1), 22-64.

(2009): “Immigration and Inequality,” NBER Working Papers 14683, National Bureau of Economic Research, Inc.

CARD, D., AND J. DiNARDo (2000): “Do Immigrant Inflows Lead to Native Outflows?," American Economic Review, 90(2), 360-367.

DAhL, G. B. (2002): "Mobility and the Return to Education: Testing a Roy Model with Multiple Markets," Econometrica, (6), 2367-2420.

Deaton, A., And D. Lubotsky (2001): "Mortality, Inequality and Race in American Cities and States," NBER Working Papers 8370, National Bureau of Economic Research, Inc.

Doms, M., AND E. LEWIS (2006): “Labor supply and personal computer adoption,” Discussion paper.

Hamermesh, D. (1993): Labor Demand. New Jersey:Princeton University Press.

Jovanovic, B. (1982): "Selection and the Evolution of Industry," Econometrica, 50(3), 649670. 
Krueger, A. B., AND J.-S. PISChKe (1997): "Observations and Conjectures on the U.S. Employment Miracle,” NBER Working Papers 6146, National Bureau of Economic Research, Inc.

LEWIS, E. (2004): "How did the Miami labor market absorb the Mariel immigrants?," Discussion paper.

MANski, C. F. (1993): "Identification of Endogenous Social Effects: The Reflection Problem," Review of Economic Studies, 60(3), 531-42.

Melitz, M. J. (2003): "The Impact of Trade on Intra-Industry Reallocations and Aggregate Industry Productivity," Econometrica, (6), 1695-1725.

Moffitt, R. A. (2001): "Policy Interventions, Low-Level Equilibria And Social Interactions," in Social Dynamics, pp. 45-82. MIT Press.

MoretTi, E. (2008): “Real Wage Inequality,” CEPR Discussion Papers 6997, C.E.P.R. Discussion Papers.

PARK, J. H. (1994): "Estimation of Sheepskin Effects and Returns to Schooling Using he Old and the New CPS Measures of Educational Attainment," Papers 338, Princeton, Department of Economics - Industrial Relations Sections.

PIssarides, C. (2000): Equilibrium Unemployment Theory. Cambridge, MA: MIT press, second edn.

Roваск, J. (1982): “Wages, Rents, and the Quality of Life," Journal of Political Economy, 90(6), 1257-78.

Roy, A. D. (1951): "Some Thoughts on the Distribution of Earnings," Oxford Economic Papers, pp. $136-146$.

Ruggles, S., M. Sobek, T. Alexander, C. A. Fitch, R. Goeken, P. K. Hall, M. King, AND C. RonNANDER (2004): Integrated Public Use Microdata Series: Version 3.0 [Machinereadable database]. Minneapolis, MN: Minnesota Population Center [producer and distributor]. 
Table 1: First Stage Results

\begin{tabular}{lccc}
\hline & \multicolumn{3}{c}{} \\
\cline { 2 - 4 } & $(1)$ & $(2)$ & $(3)$ \\
\hline$I V 1$ & $3.370^{*}$ & & $2.378^{*}$ \\
& $(0.651)$ & & $(0.635)$ \\
$I V 2$ & & $3.273^{*}$ & $2.894^{*}$ \\
& & $(0.448)$ & $(0.412)$ \\
$\sum_{i} \eta_{i, c, t-1} \cdot g_{i t}$ & 0.0237 & $0.264^{*}$ & 0.0513 \\
& $(0.0728)$ & $(0.0648)$ & $(0.0759)$ \\
\hline Observations & 33993 & 33993 & 33993 \\
$R^{2}$ & 0.485 & 0.493 & 0.497 \\
\hline
\end{tabular}

Notes: Standard errors, in parentheses, are clustered at the city-year level. $\left(^{*}\right)$ denotes significance at the $5 \%$ level. All models estimated on a sample of 152 U.S cities using Census and ACS data for 1970-2007. The dependent variable is the decadal change in log city-industry wages.

Table 2: Estimates of Job Creation Equation (16)

\begin{tabular}{lccccc}
\hline & OLS & & IV1 & IV2 & IV1\&IV2 \\
\cline { 2 - 2 } \cline { 6 - 6 } & $(1)$ & & $(2)$ & $(3)$ & $(4)$ \\
\hline$\Delta \log w_{i c t}$ & $0.125^{*}$ & $-1.022^{*}$ & $-0.932^{*}$ & $-0.954^{*}$ \\
& $(0.0158)$ & & $(0.279)$ & $(0.231)$ & $(0.221)$ \\
$\Delta \log \frac{E_{c t}}{L_{c t}}$ & $0.812^{*}$ & $-1.832^{*}$ & $-2.111^{*}$ & $-1.982^{*}$ \\
& $(0.0505)$ & & $(0.858)$ & $(0.792)$ & $(0.746)$ \\
\hline$N$ & 33993 & 33993 & 33993 & 33993 \\
$R^{2}$ & 0.506 & & & \\
F-stat $\left(\Delta \log w_{i c t}\right)$ & & 21.23 & 38.01 & 29.41 \\
F-stat $\left(\Delta \log \frac{E_{c t}}{L_{c t}}\right)$ & & 8.160 & 13.18 & 9.642 \\
Over-id(p-val.) & &. &. & 0.680 \\
\hline
\end{tabular}

NotES: Standard errors are in parentheses. $\left({ }^{*}\right)$ denotes significance at the $5 \%$ level. All models estimated on a sample of 152 U.S cities using Census and ACS data for 1970-2007. Dependent variable is the decadal change in log city-industry employment rate. 
Table 3: Estimates of Aggregate Reduced Form Specification (26)

\begin{tabular}{lccccc}
\hline & OLS & & IV1 & IV2 & IV1\&IV2 \\
\cline { 2 - 3 } \cline { 5 - 6 } & $(1)$ & & $(2)$ & $(3)$ & $(4)$ \\
\hline$\Delta R_{c t}$ & 0.0152 & $-0.709^{*}$ & $-0.636^{*}$ & $-0.661^{*}$ \\
& $(0.124)$ & & $(0.245)$ & $(0.194)$ & $(0.171)$ \\
$\sum_{i} \eta_{i, c, t-1} \cdot g_{i t}$ & $0.127^{*}$ & $0.202^{*}$ & $0.194^{*}$ & $0.197^{*}$ \\
& $(0.0371)$ & $(0.0416)$ & $(0.0349)$ & $(0.0350)$ \\
\hline $\mathrm{N}$ & 608 & 608 & 608 & 608 \\
$R^{2}$ & 0.479 & & & \\
$\mathrm{~F}-$-stat $\left(\Delta R_{c t}\right)$ & & 142.6 & 257.7 & 243.0 \\
Over-id(p-val.) & &. &. & 0.782 \\
\hline
\end{tabular}

NotES: Standard errors are in parentheses. $\left({ }^{*}\right)$ denotes significance at the $5 \%$ level. All models estimated on a sample of 152 U.S cities using Census and ACS data for 1970-2007. Dependent variable is the decadal change in log city employment rate.

Table 4: Estimates of Reduced Form Equation (27)

\begin{tabular}{lccccc}
\hline & OLS & & IV1 & IV2 & IV1\&IV2 \\
\cline { 2 - 2 } \cline { 5 - 6 } & $(1)$ & & $(2)$ & $(3)$ & $(4)$ \\
\hline$\Delta R_{c t}$ & -0.0977 & $-1.071^{*}$ & $-1.111^{*}$ & $-1.097^{*}$ \\
& $(0.178)$ & & $(0.415)$ & $(0.260)$ & $(0.258)$ \\
$\sum_{i} \eta_{i, c, t-1} \cdot g_{i t}$ & $-0.535^{*}$ & $-0.429^{*}$ & $-0.425^{*}$ & $-0.426^{*}$ \\
& $(0.0514)$ & $(0.0610)$ & $(0.0484)$ & $(0.0487)$ \\
\hline $\mathrm{N}$ & 33993 & 33993 & 33993 & 33993 \\
$R^{2}$ & 0.502 & & & \\
F-stat( $\left.\Delta R_{c t}\right)$ & & 124.6 & 256.3 & 209.8 \\
Over-id(p-val.) & &. &. & 0.922
\end{tabular}

NoTES: Standard errors, in parentheses, are clustered at the city-year level. $\left({ }^{*}\right)$ denotes significance at the 5\% level. All models estimated on a sample of 152 U.S cities using Census and ACS data for 1970-2007. Dependent variable is the decadal change in log city-industry employment rate. 
Table 5: Estimates of Aggregate Job Creation Equation (28)

\begin{tabular}{lccccc}
\hline & OLS & & IV1 & IV2 & IV1\&IV2 \\
\cline { 2 - 2 } \cline { 5 - 6 } & $(1)$ & & $(2)$ & $(3)$ & $(4)$ \\
\hline$\Delta \log w_{c t}$ & $0.126^{*}$ & & $-0.311^{*}$ & $-0.265^{*}$ & $-0.279^{*}$ \\
& $(0.0311)$ & & $(0.129)$ & $(0.0896)$ & $(0.0817)$ \\
$\sum_{i} \eta_{i, c, t-1} \cdot g_{i t}$ & $0.0917^{*}$ & $0.219^{*}$ & $0.205^{*}$ & $0.210^{*}$ \\
& $(0.0350)$ & & $(0.0565)$ & $(0.0440)$ & $(0.0445)$ \\
\hline $\mathrm{N}$ & 608 & 608 & 608 & 608 \\
$R^{2}$ & 0.497 & & & \\
F-stat $\left(\Delta \log w_{c t}\right)$ & & 33.79 & 59.48 & 39.95 \\
Over-id(p-val.) & &. &. & 0.728 \\
\hline
\end{tabular}

NoTES: Standard errors are in parentheses. $\left(^{*}\right)$ denotes significance at the $5 \%$ level. All models estimated on a sample of 152 U.S cities using Census and ACS data for 1970-2007. Dependent variable is the decadal change in log city employment rate.

Table 6: Assessing the Impact of City Size

\begin{tabular}{|c|c|c|c|c|c|c|}
\hline & OLS & IV1 & IV2 & IV1\&IV2 & IV & IV \\
\hline & (1) & (2) & (3) & (4) & (5) & (6) \\
\hline$\Delta \log w_{i c t}$ & $\begin{array}{c}0.138^{*} \\
(0.0161)\end{array}$ & $\begin{array}{l}-1.008^{*} \\
(0.327)\end{array}$ & $\begin{array}{c}-0.912^{*} \\
(0.246)\end{array}$ & $\begin{array}{l}-0.933^{*} \\
(0.241)\end{array}$ & $\begin{array}{c}-0.773^{*} \\
(0.223)\end{array}$ & \\
\hline$\Delta \log \frac{E_{c t}}{L_{c t}}$ & $\begin{array}{c}0.817^{*} \\
(0.0480)\end{array}$ & $\begin{array}{c}-1.794 * \\
(0.824)\end{array}$ & $\begin{array}{c}-2.027 * \\
(0.833)\end{array}$ & $\begin{array}{c}-1.911^{*} \\
(0.765)\end{array}$ & $\begin{array}{c}-1.286^{*} \\
(0.620)\end{array}$ & \\
\hline$\Delta \log w_{c t}$ & & & & & & $\begin{array}{c}-0.270 * \\
(0.0883)\end{array}$ \\
\hline$\sum_{i} \eta_{i, c, t-1} \cdot g_{i t}$ & & & & & & $\begin{array}{c}0.252^{*} \\
(0.0657)\end{array}$ \\
\hline$\Delta \log L_{c t}$ & $\begin{array}{c}-0.101^{*} \\
(0.0107)\end{array}$ & $\begin{array}{r}-0.00742 \\
(0.0425)\end{array}$ & $\begin{array}{l}-0.0132 \\
(0.0369)\end{array}$ & $\begin{array}{c}-0.0122 \\
(0.0369)\end{array}$ & $\begin{array}{c}-0.115 \\
(0.0721)\end{array}$ & $\begin{array}{c}-0.0373 \\
(0.0374)\end{array}$ \\
\hline $\begin{array}{l}\mathrm{N} \\
R^{2}\end{array}$ & $\begin{array}{c}33993 \\
0.508\end{array}$ & 33993 & 33993 & 33993 & 33993 & 608 \\
\hline F-stat $\left(\Delta \log w_{i c t}\right.$ or $\left.\Delta \log w_{c t}\right)$ & & 15.44 & 32.93 & 25.97 & 15.21 & 14.69 \\
\hline F-stat $\left(\Delta \log \frac{E_{i c t}}{L_{c t}}\right)$ & & 8.577 & 12.00 & 9.443 & 5.096 & $\cdot$ \\
\hline F-stat $\left(\Delta \log L_{c t}\right)$ & & & & & 24.00 & 12.34 \\
\hline Over-id(p-val.) & & . & . & 0.697 & 0.996 & 0.998 \\
\hline
\end{tabular}

NoTES: Standard errors, in parentheses, are clustered at the city-year level. $\left({ }^{*}\right)$ denotes significance at the 5\% level. All models estimated on a sample of 152 U.S cities using Census and ACS data for 1970-2007. Dependent variable is the decadal change in the log city-industry employment rate. 
Table 7: Assessing the Impact of City Skill

\begin{tabular}{|c|c|c|c|c|c|c|c|c|}
\hline & OLS & IV1 & IV2 & IV1\&IV2 & OLS & IV & OLS & IV \\
\hline & (1) & (2) & (3) & (4) & (5) & (6) & (7) & (8) \\
\hline \multirow[t]{2}{*}{$\Delta \log w_{i c t}$} & $0.125^{*}$ & $-1.037 *$ & $-0.774 *$ & $-0.849 *$ & $-1.161^{*}$ & $-1.308^{*}$ & $-0.698^{*}$ & $-0.735^{*}$ \\
\hline & $(0.0157)$ & $(0.270)$ & $(0.272)$ & $(0.221)$ & $(0.285)$ & $(0.447)$ & $(0.189)$ & $(0.217)$ \\
\hline \multirow{2}{*}{$\Delta \log \frac{E_{c t}}{L_{c t}}$} & $0.801^{*}$ & $-2.092 *$ & $-2.999 *$ & $-2.329 *$ & $-2.355^{*}$ & $-2.435^{*}$ & $-1.842^{*}$ & $-1.876^{*}$ \\
\hline & $(0.0529)$ & $(0.926)$ & $(1.229)$ & $(0.891)$ & $(0.937)$ & (1.193) & $(0.700)$ & $(0.708)$ \\
\hline \multirow{2}{*}{$\Delta \frac{\text { Efficiency Units }}{L_{c t}}$} & 0.0519 & 2.096 & 2.747 & 2.138 & & & & \\
\hline & $(0.0952)$ & $(1.285)$ & $(1.838)$ & (1.338) & & & & \\
\hline \multirow[t]{2}{*}{$\Delta \mathrm{BA}$ or $>$} & & & & & $1.901^{*}$ & 3.366 & & \\
\hline & & & & & $(0.626)$ & $(2.859)$ & & \\
\hline \multirow[t]{2}{*}{$\Delta \mathrm{SP}$ or $>$} & & & & & & & $1.645^{*}$ & 1.406 \\
\hline & & & & & & & $(0.419)$ & $(0.816)$ \\
\hline $\mathrm{N}$ & 33993 & 33993 & 33993 & 33993 & 33993 & 33993 & 33993 & 33993 \\
\hline$R^{2}$ & 0.506 & & & & & & & \\
\hline F-stat $\left(\Delta \log w_{i c t}\right)$ & & 14.22 & 25.41 & 22.08 & 28.93 & 22.15 & 27.70 & 22.03 \\
\hline F-stat $\left(\Delta \log \frac{E_{i c t}}{L_{c t}}\right)$ & & 6.577 & 10.24 & 8.098 & 9.185 & 7.918 & 7.150 & 8.168 \\
\hline Fstat(Educ.Var.) & & 21.85 & 27.65 & 21.99 & - & 14.57 & . & 25.24 \\
\hline Over-id(p-val.) & & . & . & 0.292 & 0.377 & 0.268 & 0.108 & 0.197 \\
\hline
\end{tabular}

NOTES: Standard errors, in parentheses, are clustered at the city-year level. $\left({ }^{*}\right)$ denotes significance at the $5 \%$ level. All models estimated on a sample of 152 U.S cities using Census and ACS data for 1970-2007. Dependent variable is decadal changes in log city-industry employment rate.

Table 8: Results by Education Group

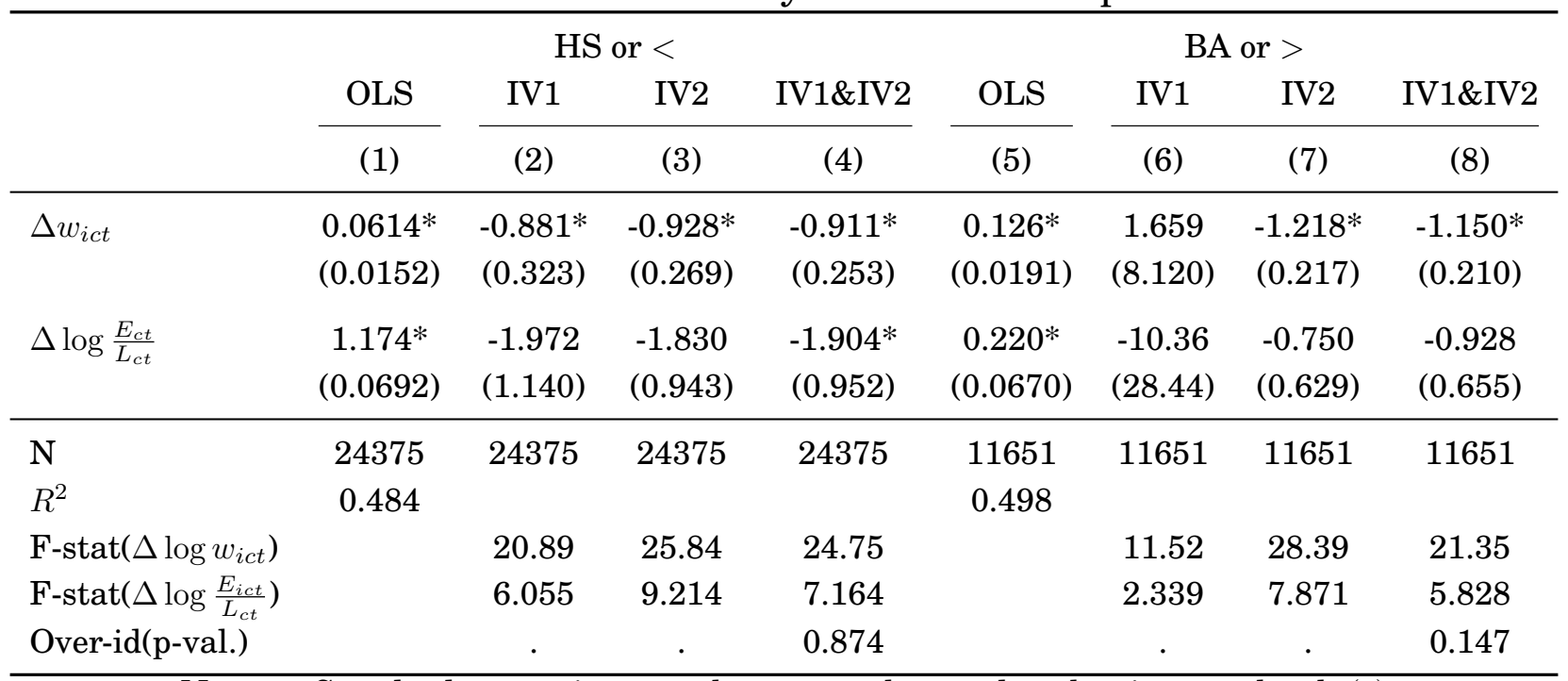

NoTES: Standard errors, in parentheses, are clustered at the city-year level. $\left(^{*}\right)$ denotes significance at the 5\% level. All models estimated on a sample of 152 U.S cities using Census and ACS data for 1970-2007. Dependent variable is the decadal change in log city-industry employment rate. 
Table 9: Further Model Implications

\begin{tabular}{|c|c|c|c|c|c|c|c|c|}
\hline & OLS & IV1 & IV2 & IV1\&IV2 & OLS & IV1 & IV2 & IV1\&IV2 \\
\hline & (1) & (2) & (3) & (4) & (5) & (6) & (7) & (8) \\
\hline \multirow[t]{2}{*}{$\log w_{c t}$} & $0.460 *$ & $1.993^{*}$ & $1.309 *$ & $1.523^{*}$ & $1.352^{*}$ & $1.865^{*}$ & $1.677^{*}$ & $1.735^{*}$ \\
\hline & $(0.179)$ & $(0.559)$ & $(0.538)$ & $(0.464)$ & $(0.116)$ & $(0.394)$ & $(0.322)$ & $(0.311)$ \\
\hline \multirow[t]{2}{*}{$\Delta \log E R_{c t}$} & -0.0260 & $4.927^{*}$ & $6.479 *$ & $5.829 *$ & 0.161 & $1.999 *$ & $2.425^{*}$ & $2.247^{*}$ \\
\hline & $(0.200)$ & (1.788) & (1.601) & (1.532) & $(0.170)$ & $(0.924)$ & $(0.987)$ & $(0.883)$ \\
\hline $\mathrm{N}$ & 608 & 608 & 608 & 608 & 608 & 608 & 608 & 608 \\
\hline$R^{2}$ & 0.179 & & & & 0.523 & & & \\
\hline F-stat $\left(\log w_{c t}\right)$ & & 27.46 & 41.80 & 33.27 & & 27.46 & 41.80 & 33.27 \\
\hline Over - id & & & & 0.244 & & & & 0.567 \\
\hline
\end{tabular}

NoTES: Standard errors are in parentheses. $\left({ }^{*}\right)$ denotes significance at the $5 \%$ level. All models estimated on a sample of 152 U.S cities using Census and ACS data for 1970-2007. Dependent variable is either the decadal change in log labor force size or rental rate of a two or three bedroom apartment. 